\title{
Analysis of gravity-waves produced by intense tropical cyclones
}

\author{
F. Chane Ming ${ }^{1}$, Z. Chen ${ }^{2}$, and F. Roux ${ }^{3}$ \\ ${ }^{1}$ Laboratoire de l'Atmosphère et des Cyclones, UMR 8105, CNRS-Météo-France, Université de la Réunion, La Réunion, \\ France \\ ${ }^{2}$ Institute of Atmospheric Physics - Chinese Academy of Sciences, Beijing, China \\ ${ }^{3}$ Laboratoire d'Aérologie, UMR CNRS - Université Paul Sabatier, Toulouse, France
}

Received: 19 June 2009 - Revised: 27 January 2010 - Accepted: 31 January 2010 - Published: 15 February 2010

\begin{abstract}
Conventional and wavelet methods are combined to characterize gravity-waves (GWs) produced by two intense tropical cyclones (TCs) in the upper troposphere and lower stratosphere (UT/LS) from GPS winsonde data. Analyses reveal large contribution of GWs induced by TCs to wave energy densities in the UT/LS. An increase in total energy density of about $30 \%$ of the climatological energy density in austral summer was estimated in the LS above Tromelin during TC Dina. Four distinct periods in GW activity in relation with TC Faxai stages is observed in the UT. Globally, GWs have periods of $6 \mathrm{~h}-2.5$ days, vertical wavelenghts of $1-3 \mathrm{~km}$ and horizontal wavelengths $<1000 \mathrm{~km}$ in the UT during the evolution of TCs. Horizontal wavelengths are longer in the LS and about $2200 \mathrm{~km}$ during TCs. Convective activity over the basin and GW energy density were modulated by mixed equatorial waves of 3-4 days, 6-8 days and 10-13 days confirmed by Hövmöller diagram, Fourier and wavelet analyses of OLR data. Moreover, location of GW sources is below the tropopause height when TCs are intense otherwise varies at lower tropospheric heights depending on the strength of convection. Finally, the maximum surface wind speeds of TCs Dina and Faxai can be linearly estimated with total energy densities.
\end{abstract}

Keywords. Meteorology and atmospheric dynamics (Middle atmosphere dynamics; Tropical meteorology; Waves and tides)

\section{Introduction}

Gravity-waves (GWs) produced by tropical cyclone-induced convection impact on the dynamics as well as the distribution of chemical constituents of the Earth's middle atmo-

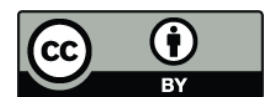

Correspondence to: F. Chane Ming (fchane@univ-reunion.fr) sphere (Sato, 1993; Pfister et al., 1993; Danielsen, 1993; Dhaka et al., 2003; Cairo et al., 2008). Chane Ming et al. (2002) showed that such GWs can be characterized using high resolution daily radiosonde data in the UT/LS within a radius of about $2000 \mathrm{~km}$ above the radiosonde station. For instance, significant release of GW energy was observed during landfalls of TC Hudah over Madagascar and Mozambique. Observations of GWs also appear to be common in landfalling tropical cyclones (TCs) in atmospheric boundary layer when cool surface temperatures promote stable conditions over land (Knupp et al., 2006). When propagating up to the upper atmosphere, GWs excited by TCs (Shen, 1982; Sun et al., 2007) bring forth the observable traveling ionospheric disturbances (TIDs) in the form of ionization in the F-region (Hung, 1977a, b). Using a reverse ray tracing technique, Hung and Kuo (1978a) and Hung and Smith (1978b) identified tropical cyclones as possible sources of GWs at the ionospheric heights.

Other than convective GWs, spontaneously inertia-gravity waves can be radiated to the environment by intense mesoscale vortices such as TCs (Schecter and Montgomery, 2006). The multiscale numerical study of hurricane Andrew previously showed evidence of instantaneous GWs in the eye, more intense above the warm core along the inner edge of the eyewall supporting that GWs in addition with vortex Rossby waves also play a role in determining the time evolution of the inner core structure (Liu et al., 1999; Yau et al., 2004). Moreover Shibagaki et al. (2003) interpreted the observed outflow regions tilted outward with height in front of the typhoon Orchid as internal inertia-gravity waves, proposed as a mechanism of outward-propagating rainbands. Chow and Chan (2003) argued that a significant amount of angular momentum can effectively radially be removed from the inner core by outgoing spiral waves. Recent numerical studies concluded that such radiation has a smaller impact than surface drag and vorticity mixing on TC intensity change (Schecter, 2008; Hendrick et al., 2008). 


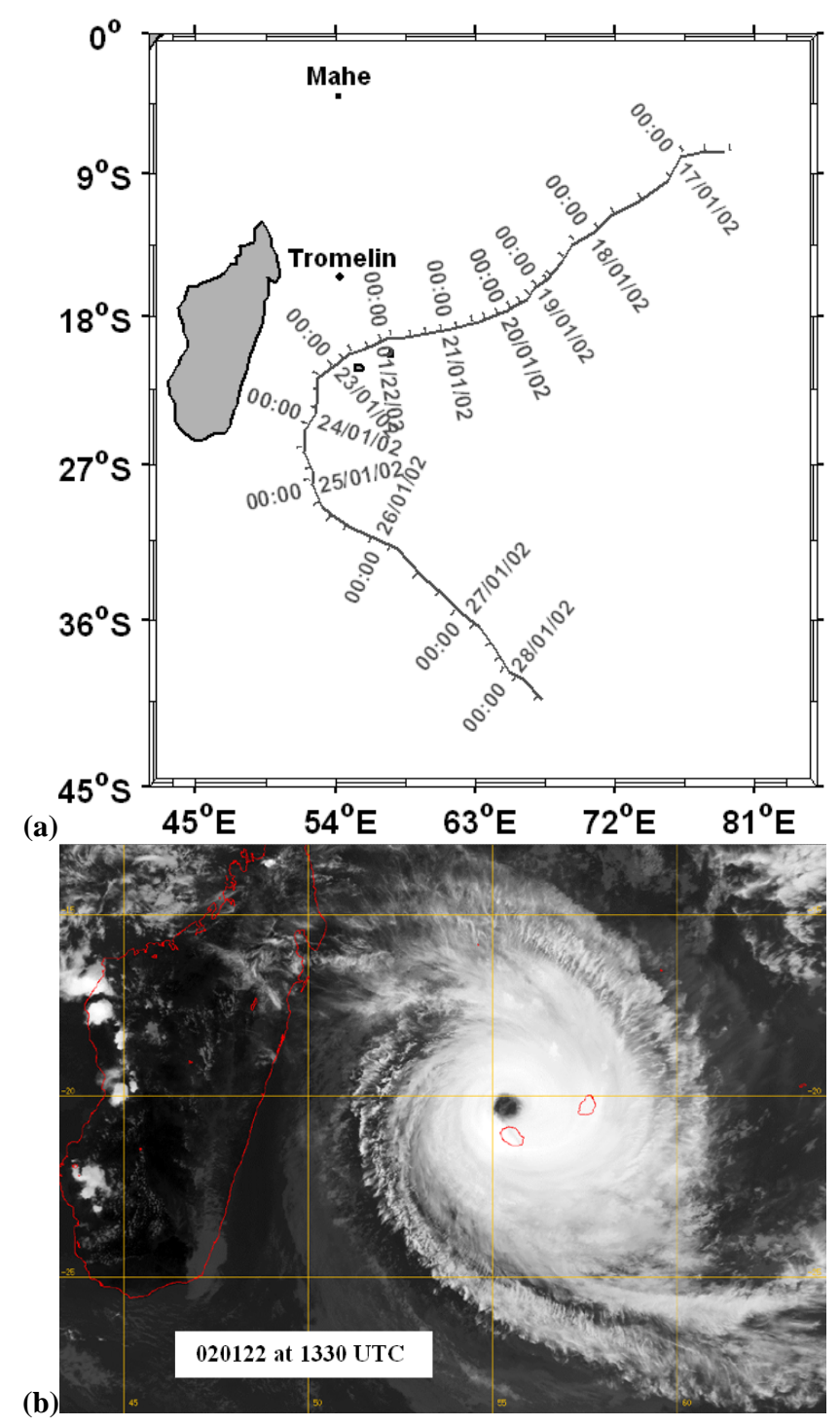

Fig. 1. (a) Best track of tropical cyclone Dina from 17 to 26 January 2002 and (b) MétéoSat 5 infrared image of TC Dina at closest distance of La Reunion on 22 January at 13:30 UTC. (RSMC La Réunion).

For comparison with observations, Kim et al. (2005) analyzed the characteristics of typhoon-generated GWs with the mesoscale model MM5. Numerical modeling study of convective GWs generated by Typhoon Rusa pointed out the importance of eastward propagating convective GWs in the middle latitudes as a significant source of positive momentum forcing in the summer mesosphere. Sensitivity of typhoon-induced GWs to cumulus parameterizations and the resulting differences in spectral characteristics of stratospheric GWs were recently investigated (Kim at al., 2007).

In the current research, the characteristics of the GWs induced by two TC cases, i.e., TC Dina in the South-West In- dian Ocean (SWIO) and TC Faxai in the North-West Pacific ocean (NWPac), are investigated. The two TCs exhibit similar aspects, for example, track, intensity evolution and duration. GW signals are retrieved by using conventional and wavelet analyses from GPS windsonde data.

GW energy activity related to TC intensity as well as the variability of the convective activity of the basin are also investigated.

\section{Observation of intense tropical cyclones Dina and Faxai}

After the evolution of severe tropical storm Cyprien in the Mozambique Channel from 30 December to 3 January 2001, TC Dina formed on 16 January 2002 from a large convection east of Diego Garcia ( $\left.8.8^{\circ} \mathrm{S}, 76.8^{\circ} \mathrm{E}\right)$ in the SWIO (Fig. 1a). On 18 January, the storm was classified as a TC by the Tropical Cyclone Warning Centre of Meteo-France on La Reunion island. It was moving with a propagation speed of about 6$7 \mathrm{~m} \mathrm{~s}^{-1}$ and intensified on 19 January reaching its maximum intensity of about $70 \mathrm{~m} \mathrm{~s}^{-1}$ with a minimum surface pressure of $910 \mathrm{hPa}$ in the morning of 20 January. At this time the eye and the cloud shield were $25 \mathrm{~km}$ and $300 \mathrm{~km}$ wide, respectively. From the afternoon of 20 to 22 January, the surface wind and pressure weakened to $60-65 \mathrm{~m} \mathrm{~s}^{-1}$ and from 910 to $920 \mathrm{hPa}$ and its direction of propagation changed to west-southwestward. Dina's eye was located at closest distance from Mauritius at 23:15 UTC on 21st with a minimum distance of $65 \mathrm{~km}$ and later from La Réunion on 22 January with a minimum distance of $65 \mathrm{~km}$ from the northern coast at 13:30 UTC (Fig. 1b). Strong winds ranging from 50 to $70 \mathrm{~m} \mathrm{~s}^{-1}$ and heavy rain (accumulated of 500 to $2000 \mathrm{~mm}$ in $72 \mathrm{~h}$ ) were observed over La Réunion. On 23 January, Dina's trajectory changed to southward and its intensity decreased rapidly. The storm continued to move quickly to the southeast from 24 January and the extratropical storm was later evacuated by the mid-latitude circulation. The GroundBased Extended Velocity Track Display techniques applied to Doppler radar observations of TC Dina at la Réunion revealed low values of Doppler radar reflectivity $<20 \mathrm{dBZ}$ in the eye at radii smaller than $30 \mathrm{~km}$ and strong $(>40 \mathrm{dBZ}$ ) and elevated ( $15 \mathrm{dBZ}$ limit up to $10-11-\mathrm{km}$ altitude) ones in the eyewall region at radii between 30 and $80 \mathrm{~km}$ which are characteristic of intense tropical cyclone (Roux et al., 2004). In addition the blocking effect of the topography of the island was suggested as the cause of the observed changes in the location and intensity of the maximum winds of TC Dina during its passage at the north coast of La Réunion.

TC Faxai was a super typhoon in December 2001 in the Pacific. It evolved from a tropical depression southeast of Pohnpei Island at 18:00 UTC on 13 December (Fig. 2a). The deep convection remained unorganized and sheared until 15th. It developed into a tropical storm on 16 December at about $2000 \mathrm{~km}$ away from Guam island (Mariana 


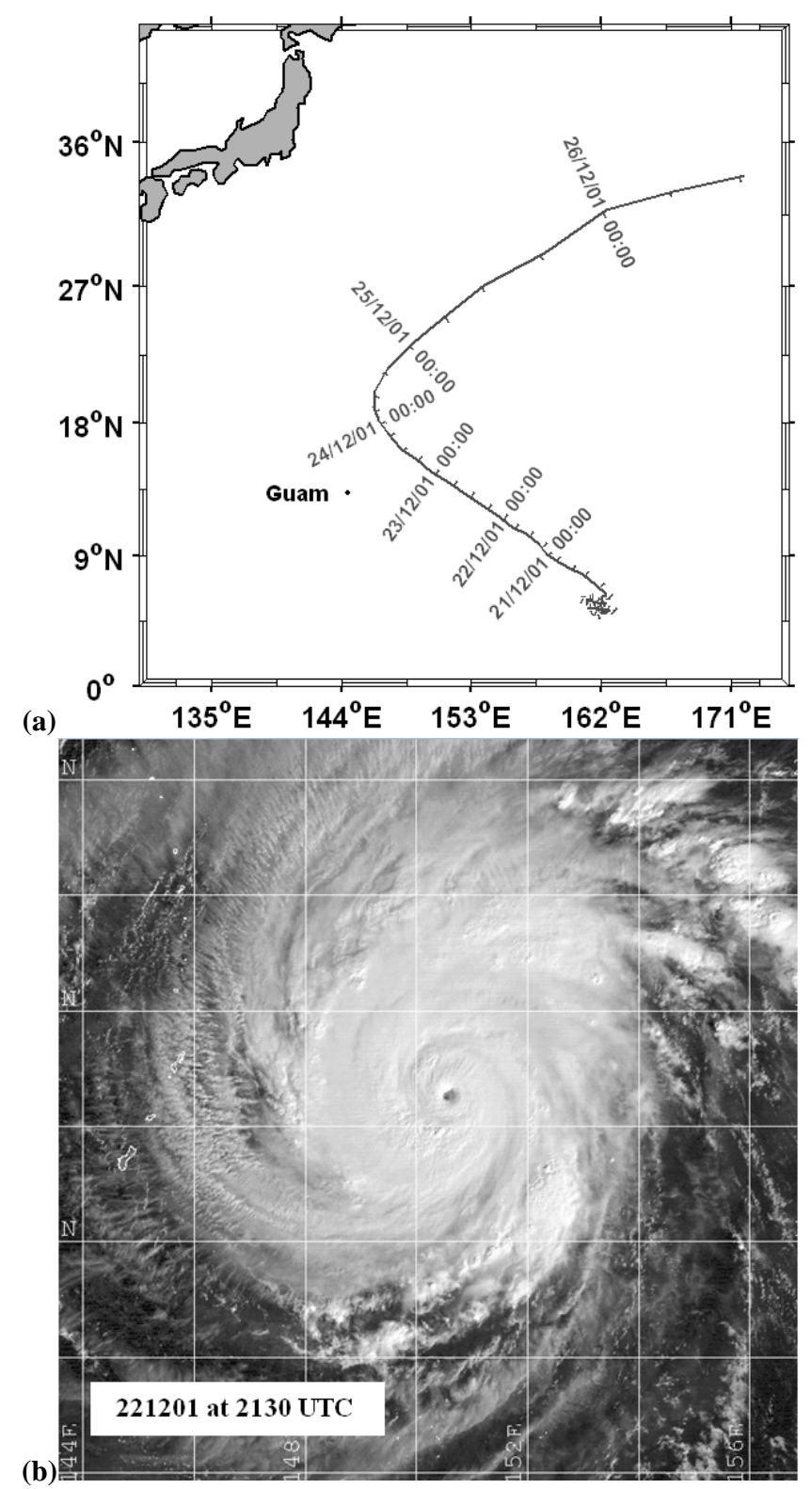

Fig. 2. (a) Best track of TC Faxai from 14 to 26 December 2001 and (b) GMS-5 Vis satellite image of TC Faxai near its peak intensity on 22 December at 21:30 UTC. (Naval Research Laboratory).

Islands) and then remained quasi-stationary for nearly four days. The depression was upgraded to tropical storm Faxai by the Japan Meteorological Agency-RSMC Tokyo-Typhoon Center at 18:00UTC.

When moved northwestward, Faxai gradually intensified into a typhoon on the 20th and rapidly a very intense cyclone on 22 December. Its eye diameter and cloud shield was about $32 \mathrm{~km}$ and $900 \mathrm{~km}$ wide respectively (Fig. 2b). Faxai reached its peak intensity at 00:00 UTC on 23 December with gust winds of $80 \mathrm{~m} \mathrm{~s}^{-1}$ and minimum pressure of $879 \mathrm{hPa}$. Af- terwards, the TC gradually weakened as recurved over the North of Mariana Islands on 24 December, and further downgraded into an extratropical storm on 25 December.

\section{Data description}

\subsection{Datasets}

The dataset for the study of TC Dina consists of high resolution meteorological radiosonde data with 100-m vertical resolution (20-s intervals) (Chane Ming et al., 2007). Vertical profiles of temperature and horizontal wind have resolution of $0.1 \mathrm{~K}$ and $<1 \mathrm{~m} \mathrm{~s}^{-1}$. During January 2002, 20 (27) vertical profiles of temperature and horizontal wind at 00:00 UTC (12:00 UTC) produced by twice-daily launched GPS radiosondes are available at heights $<25 \mathrm{~km}$ above Mahe $\left(4.66^{\circ} \mathrm{S}, 55.53^{\circ} \mathrm{E}\right)$. GW activity above Mahe is characterized at 12:00 UTC because the dataset includes 9 profiles during the evolution of Dina (16-25 January) in the UT (10-15 km) and 6 vertical profiles in the LS (19-25 km). 23 (17) vertical profiles of temperature and horizontal wind produced by daily launched GPS radiosondes were selected for January 2002 to characterize GW activity at heights of $10-15 \mathrm{~km}(18-23 \mathrm{~km})$ above Tromelin $\left(15.53^{\circ} \mathrm{S}, 54.31^{\circ} \mathrm{E}\right)$. 9 vertical profiles are analyzed during the evolution of Dina (16-25 January) in the UT and LS. A high activity of TCs is observed in the vicinity of Tromelin as opposed to Mahe which is located in the equatorial area (Kuleshov and de Hoedt, 2003).

Twice-daily launched radiosonding data at Guam island $\left(13.46^{\circ} \mathrm{N}, 144.78^{\circ} \mathrm{E}\right)$, i.e., at 00:00 and 12:00 UTC, respectively, are used to estimate the GWs relating to TC Faxai as it propagated nearby the island. These are high resolution temperature and wind profiles with $30-\mathrm{m}$ vertical intervals (6-s intervals). A total of 54 (45) profiles provides GW analysis at height ranges of $10-16 \mathrm{~km}$ and $19-25 \mathrm{~km}$, respectively. Among them, there are more than 30 profiles in period 1128 December.

\subsection{Methods of analysis}

Second and third order polynomial fits are respectively applied to $100-\mathrm{m}$ vertical profiles of temperature and wind obtained by a cubic spline interpolation. Temperature and wind perturbations of GWs are extracted from the difference between resampled vertical profiles and associated polynomial fits (Allen and Vincent, 1995; Vincent et al., 1997). Then, conventional and wavelet analyses are combined to investigate efficiently GW spectral characteristics using the perturbations thus obtained.

1. The hodograph analysis (Cot and Barat, 1986) retrieves GW characteristics from the elliptical structures of horizontal wind perturbations from instant vertical profiles. A new efficient direct method is here used for fitting 
ellipses with a numerically stable non-iterative algorithm based on a least square minimization guarantying an ellipse-specific solution for scattered or noisy data (Halir and Flusser, 1998; Fitzgibbon et al., 1999). Assuming linear theory without wind shear, the intrinsic frequency of the wave normalized by the inertial frequency $f$ is derived from the ratio of the major axis a to the minor axis b of the ellipse (Gill, 1982). Uncertainties of the commonly used hodograph method to characterize GWs are illustrated in Zhang et al. (2004). Mean values of the major and minor axes as a function of height can also be computed with variances of horizontal wind perturbations.

$\overline{a^{2}}=\operatorname{var}\left(u^{\prime}\right)+\operatorname{var}\left(v^{\prime}\right)+\operatorname{sqrt}\left(\left(\operatorname{var}\left(u^{\prime}\right)-\operatorname{var}\left(v^{\prime}\right)\right)^{2}+4^{*}{\overline{u^{\prime} v^{\prime}}}^{2}\right)$

$\overline{b^{2}}=\operatorname{var}\left(u^{\prime}\right)+\operatorname{var}\left(v^{\prime}\right)-\operatorname{sqrt}\left(\left(\operatorname{var}\left(u^{\prime}\right)-\operatorname{var}\left(v^{\prime}\right)\right)^{2}+4^{*}{\overline{u^{\prime} v^{\prime}}}^{2}\right)$

The axis ratio provides the intrinsic frequency normalized by the inertial frequency hereinafter called the normalized intrinsic frequency.

$\frac{\omega^{*}}{f}=\frac{a}{b}$

where var denotes the variance, $u^{\prime}$ and $v^{\prime}$ are the zonal and meridional wind perturbations, $\omega^{*}$ and $f$ are the intrinsic frequency and the inertial frequency, respectively, the overbar corresponds to height average. The direction of horizontal wave propagation oriented clockwise from north (hereinafter noted Phi) is here derived from the direction of the major axis with an uncertainty of $\pi \mathrm{rad}$.

2. The method of SPARC Gravity Wave Initiative Radiosonde Data Analysis is based on the GW spectra theory and the rotary spectra analysis. The mean direction of horizontal wave propagation is calculated with the ratio of the vertical fluxes of zonal and meridional momentum per unit mass using the Hilbert-transform of temperature perturbations (Vincent et al., 1997). In the present study, the modified Desaubies spectrum model is subtracted from the energy spectrum to extract dominant vertical wavelengths. Wave energy propagates upward when fraction of upward energy $\left(F_{\text {up }}\right)$ is $>50 \%$ otherwise it propagates downward.

3. The Stokes parameter method provides a good description of polarized waves such as GWs (Vincent and Fritts, 1987). Eckermann and Vincent (1989) computed statistics of parameters for example the degree of polarization, the axial ratio and the direction of the horizontal wave propagation. The Fast Fourier Transform based method is here applied on the dataset (Eckermann, 1996).
4. Unlike the other methods, that proposed by Guest et al. $(2000,2002)$ considers each vertical profile as a time profile. The apparent frequency is then derived from the energy spectrum. The vertical wavenumber is computed using the apparent frequency and the intrinsic frequency derived from the Stokes method. Doppler shifting of the wave field by both the balloon and the background wind is taken into account by the method.

5. The wavelet analysis detects GW signatures on instant vertical profiles of temperature and horizontal winds using the Morlet Continuous Wavelet Transform (CWT) applied on simplified linear wave polarization relations (Chane Ming et al., 2002, 2003).

Energy density defined in the three-dimensional model of GW power spectrum is used as a measure of GW activity (Vincent et al., 1997). It is directly calculated with temperature and horizontal wind perturbations (Chane Ming et al., 2007).

Conventional methods are tested on simulated vertical profiles of GWs based on the simplified linear wave polarization relations for vertical wavelengths ranged from 0.5 to $6 \mathrm{~km}$ and different values of normalized intrinsic frequency and horizontal direction (Gill, 1982). Combining method 2 for energy densities, the mean direction of horizontal wave propagation and the $F_{\text {up }}$, method 3 for the axial ratio and the period, and method 4 for the vertical and horizontal wavelengths provides good estimation of GW parameters. The horizontal wavelength parameter is derived from the dispersion equation for GWs.

\section{Results}

\subsection{Case of TC Dina}

The examination of vertical profiles of temperature and wind shows evidence of small-scaled perturbations over Tromelin and Mahe during the activity of TC Dina. Large amplitudes of perturbation are observed as the intensity of TC Dina increases from 20 January to 24 January 2002 (Figs. 3 and 4). Dominant northward (southward) horizontal wind at height below $10 \mathrm{~km}$ before 21 January (after 23 January) is consistent with the location of TC Dina at this time (Fig. 1). Westward wind stronger than $20 \mathrm{~m} \mathrm{~s}^{-1}$ is observed above $10 \mathrm{~km}$ height at Tromelin. Similar observation is noticed above Mahe on 21 January at heights between $5 \mathrm{~km}$ and $22 \mathrm{~km}$ but with weak intensity of zonal wind up to $10-\mathrm{km}$ height. Small values of eastward wind at heights above $21 \mathrm{~km}$ agree well with the beginning of the westerly phase of the quasi-biennal oscillation in 2002. Thus, analysis of radiosondes clearly indicates that Tromelin is under the direct influence of TC Dina on 22 and 23 January. 

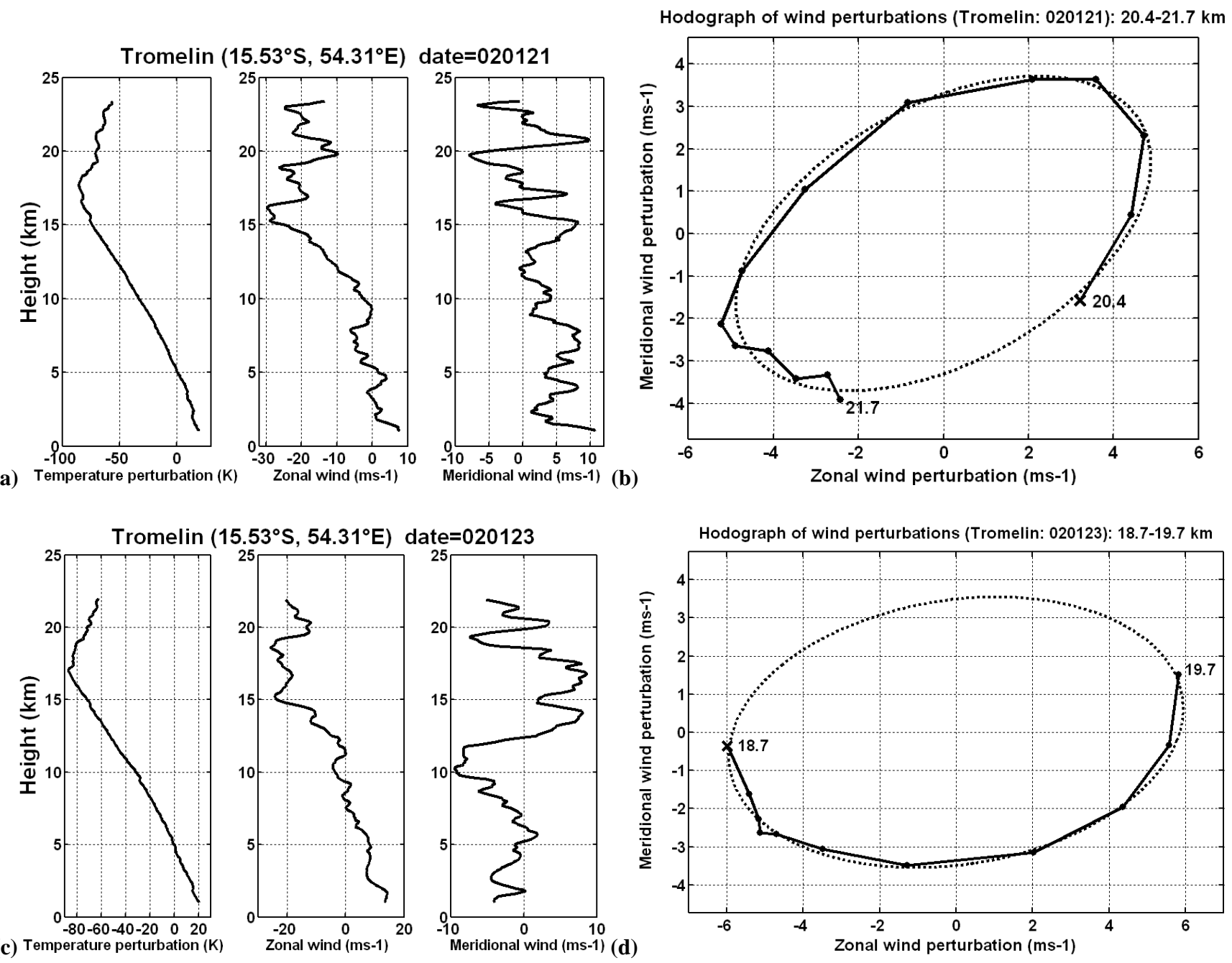

Fig. 3. Vertical profiles of temperature and horizontal winds on (a) 21 January, (c) 23 January 2002 and respective hodogaphs (solid line) with the fitting ellipse (dotted line) of horizontal wind perturbations in the lower stratosphere (b) and (d) at Tromelin. $\mathrm{x}$ and points indicate the starting point of the hodograph and each 100-m height, respectively.

\subsubsection{Hodograph analysis}

Horizontal wind perturbations are extracted from vertical profiles using a second-order polynomial for the hodograph analysis. Perturbations of about $6-8 \mathrm{~m} \mathrm{~s}^{-1}$ are observed in the LS. Figures 3 and 4 reveal the presence of elliptical patterns of anti-cyclonic nature which are characteristic of quasi-monochromatic GW structures with upward propagating wave energy in the LS above Tromelin and Mahe respectively. On 23 January, a quasi-monochromatic structure is detected at $19-\mathrm{km}$ height at Tromelin with about $1.8 \mathrm{~km}$ vertical wavelength, an axis ratio of 1.7 and Phi of $60-90^{\circ}$ ( $\pm 180^{\circ}$ of uncertainties). A similar structure is observed at $23-\mathrm{km}$ height at Mahe with about $1.6 \mathrm{~km}$ vertical wavelength and an axis ratio of 2.9. The normalized intrinsic frequencies vary between 1.2 and 2.2 (periods of $0.83-1.5$ days) above
Tromelin and between 1.6 and 4.1 (periods of 1.5-3.8 days) above Mahe during 20-24 January. The hodograph analysis is known to well-adapted to monochromatic structures but fails when multiple wavelike structures are present. Narrow bandwidth filtering is commonly used to extract complete elliptical structures from vertical profiles of perturbations but it can significantly alter the amplitudes of perturbations and consequently biased computed normalized intrinsic frequency and more particularly the horizontal direction of wave propagation (Zhang et al., 2004). Nevertheless, the application of a narrow bandwidth filtering on wind perturbations also confirms the presence of complete elliptical structures during TC Dina. A 5-km running mean is used to produce vertical profiles of the normalized intrinsic frequencies from 20 January to 24 January above Tromelin using the variance method of Eq. (1). Figure 5 confirms that normalized 


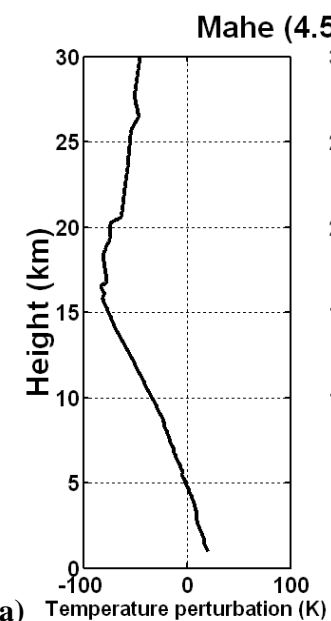

(a)

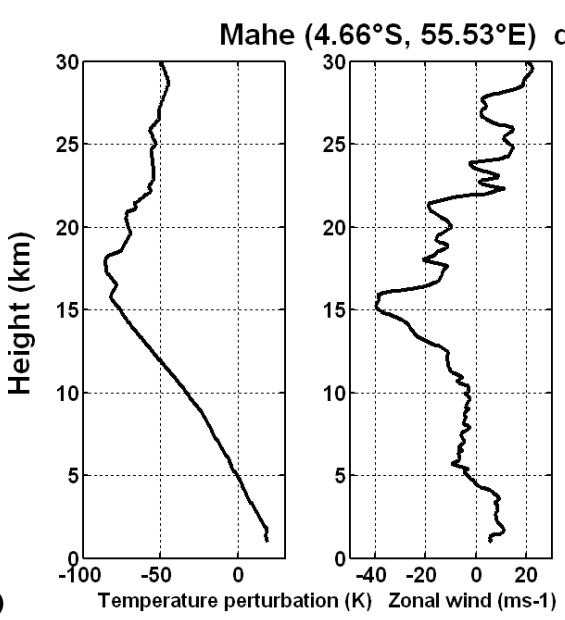

(c)
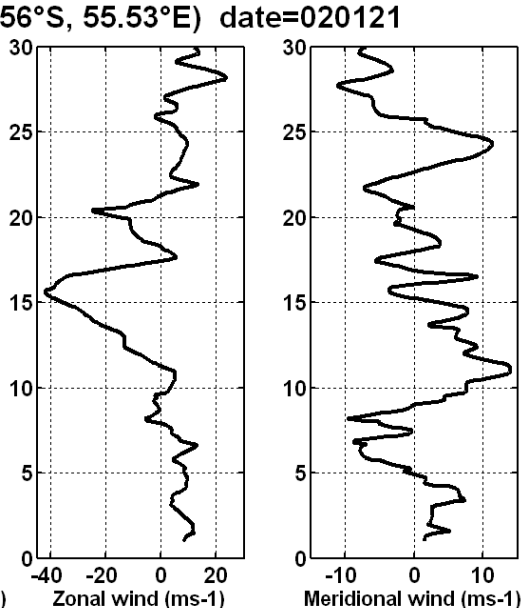

Meridional wind (ms-1) (b)

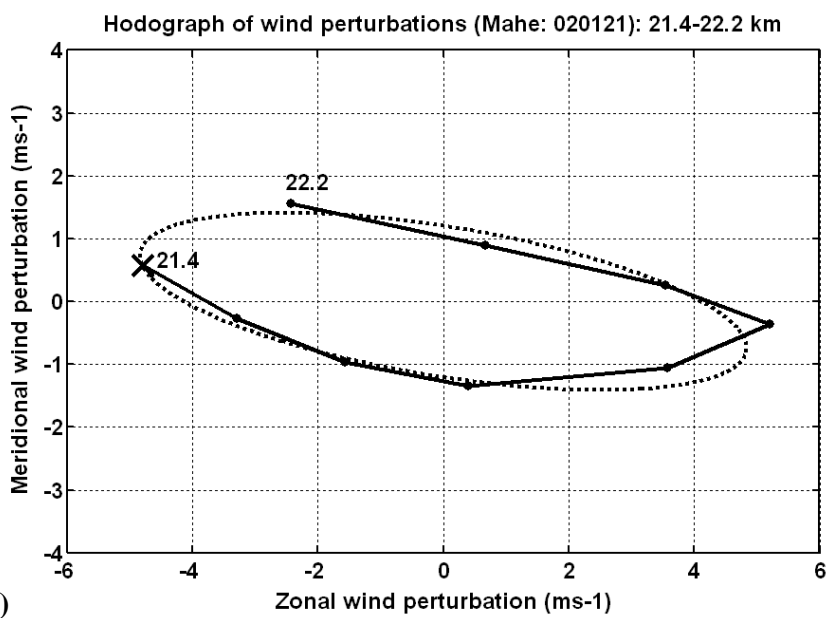

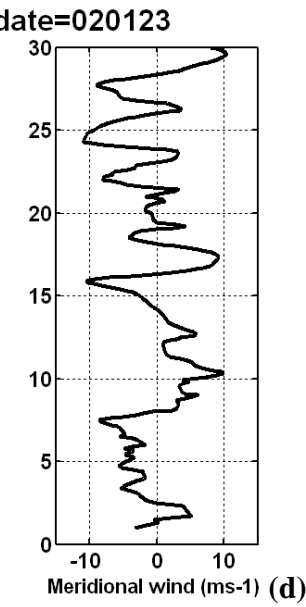

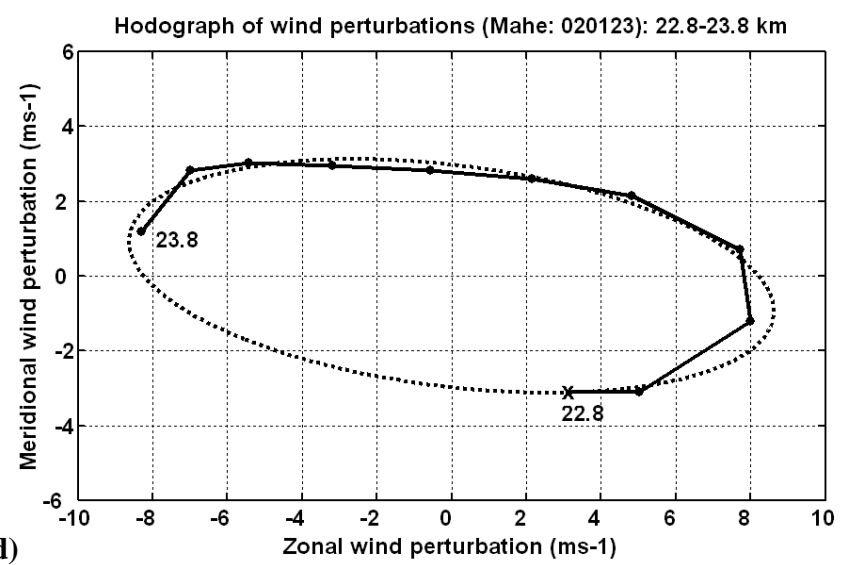

Fig. 4. Same as Fig. 3 but at Mahe.

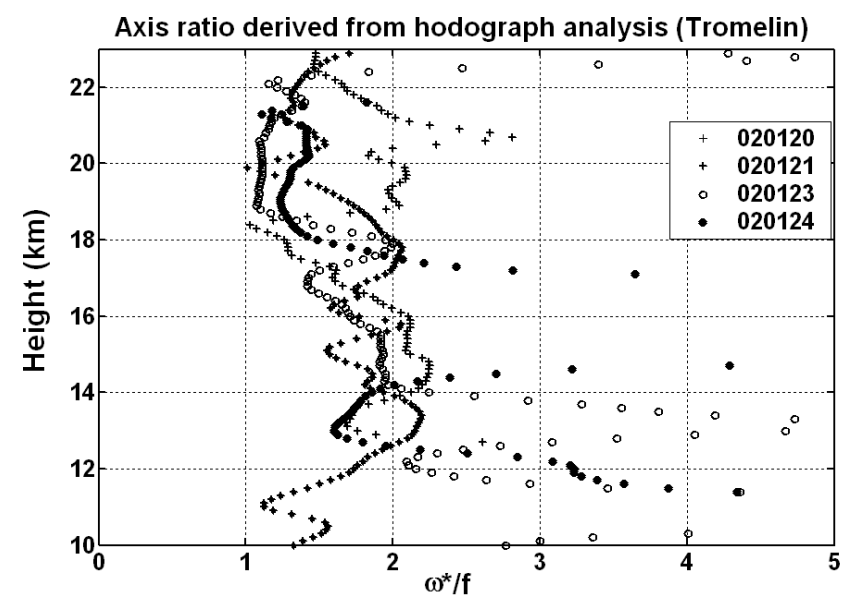

Fig. 5. Vertical profiles of 5-km running mean intrinsic frequencies from 20 January to 24 January 2002 above Tromelin. intrinsic frequency varies between 1.5 and 2.2 at heights in the UT with smaller mean values of about 1.2 at heights in the LS. Observation of steady values of normalized intrinsic frequencies over UT/LS height ranges is consistent with the presence of elliptical structures on hodographs of wind perturbations during the passage of TC Dina above Tromelin.

\subsubsection{Application of CWT analysis}

As an illustration, CWT analysis is applied on vertical profiles of temperature and wind perturbation on 23 January at Tromelin. For example, vertical wavelength-height diagram of modulous of CWT coefficients reveals the signature of a quasi-monochromatic structure on temperature perturbations with vertical wavelength of about $2.4 \mathrm{~km}$ at height range of $15-22 \mathrm{~km}$ (Fig. 6a). The derived histogram of local CWT maximum identifies vertical wavelengths of $0.8 \mathrm{~km}, 1.7-2.5 \mathrm{~km}$ and $3.5 \mathrm{~km}$ at heights of $18-21 \mathrm{~km}$ on 23 January (Fig. 6b). The wavelet analysis detects the GW structure of $2.4 \mathrm{~km}$ vertical wavelength as a coherent mode 


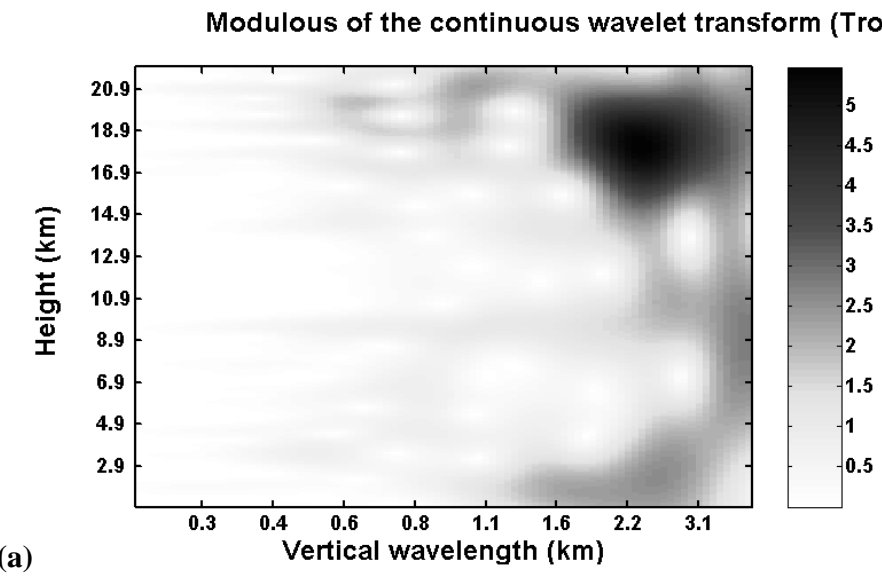

elin : 020123)

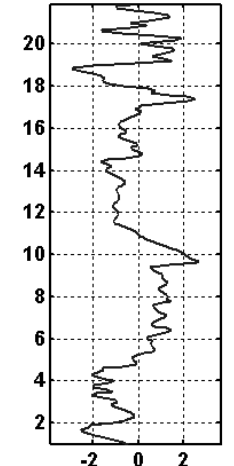

Temperature perturbation $(\mathrm{K})$

Wavelet analysis (Tromelin: 020123) (a)

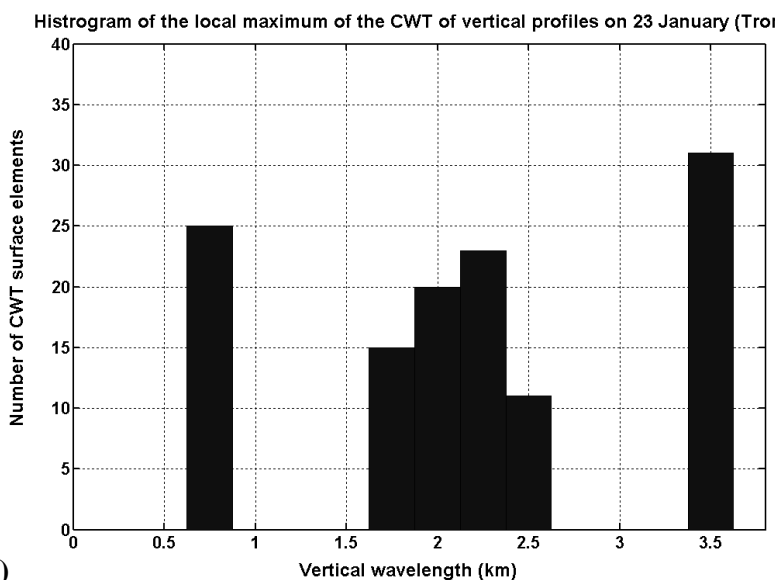

(b)

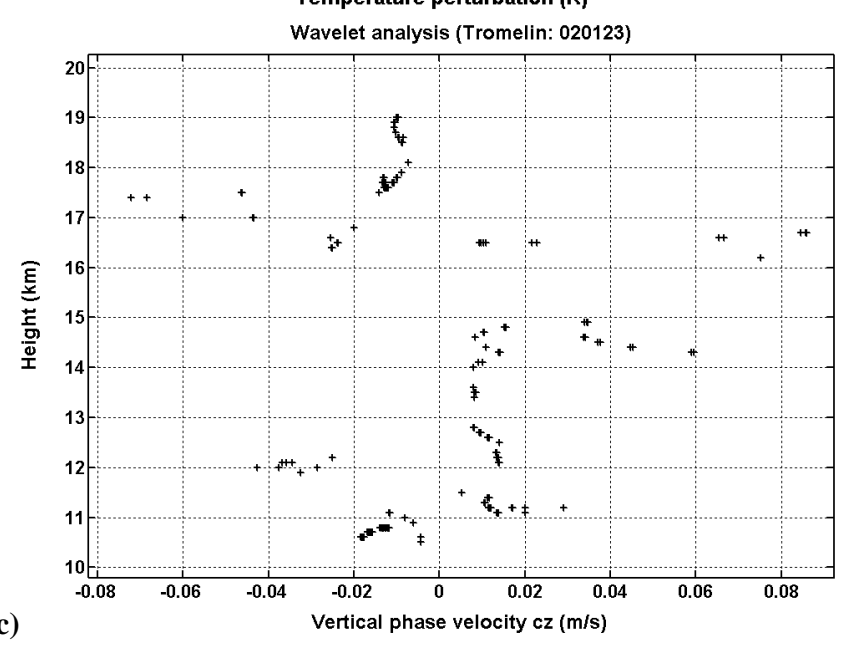

Fig. 6. Continuous wavelet transform applied on vertical profiles of temperature and horizontal winds observed above Tromelin on 23 January. (a) vertical wavelength-height diagram of CW modulous for temperature perturbations, (b) histogram of the CWT local maximum and (c) the vertical phase speed-height diagram for the coherent gravity-wave with $2.4 \mathrm{~km}$ vertical wavelength detected by the wavelet analysis.

with normalized intrinsic frequency peaking at 2. Horizontal wavelengths are predominantly $<500 \mathrm{~km}$ in the UT whereas longer wavelengths $<2000 \mathrm{~km}$ are observed in the LS with mean values between $500 \mathrm{~km}$ and $1200 \mathrm{~km}$. Using linear polarization wave equation, differences in values of the Brünt Väisälä frequency and normalized intrinsic frequency (Fig. 5) in the UT/LS partially explain the observed values of horizontal wavelengths. Figure $6 \mathrm{c}$ visualizes positive (negative) vertical phase speeds of about $0.01 \mathrm{~m} \mathrm{~s}^{-1}$ at heights between 11 and $15 \mathrm{~km}$ in the UT (17 and $19 \mathrm{~km}$ in the LS) which correspond to downward (upward) propagating energy of the $2.4 \mathrm{~km}$ vertical wavelength mode. Moreover, this last figure also informs that the GW source is probably localized at heights between 15 and $17 \mathrm{~km}$.

\subsubsection{GW parameters derived from combined methods}

Table 1 gathers mean values of GW parameters computed using conventional methods above Tromelin and Mahe in
January 2002. GWs with upward propagating wave energy are globally dominant in the UT/LS especially in the LS $\left(F_{\text {up }} \geq 70 \%\right)$. More mixed vertical propagation of wave energy is observed in the UT. GWs have periods of 1.5 days, vertical wavelengths of about $1 \mathrm{~km}$ and $2.6 \mathrm{~km}$ and horizontal wavelengths of about $800 \mathrm{~km}$ and $2000 \mathrm{~km}$ above Tromelin. Long horizontal wavelengths are observed in the LS. Above Mahe, similar spectral characteristics are observed in the UT but with longer periods of 1.8-2.7 days. Horizontal wavelengths of $450 \mathrm{~km}$ and $1100 \mathrm{~km}$ with periods of 1.79 days are detected in the LS. Mean horizontal wave propagation is north-eastward $\left(\mathrm{Phi}=60-75^{\circ}\right)$ above the two sites in the UT/LS in January 2002 while the zonal wind is westward at heights between $10 \mathrm{~km}$ and $22 \mathrm{~km}$. Values also indicate a dominant kinetic energy density in the UT and a noticable increase in potential energy density in the LS. Total energy density is 2.6 times larger above Mahe than that observed above Tromelin in the LS (Chane Ming et al., 2007). In addition, the ratio $E_{\mathrm{k}} / E_{\mathrm{p}}$ of about 1.2 in the LS above Tromelin 
Table 1. GW parameters in the UT/LS above Tromelin (Mahe) at 12:00 UTC in January 2002 using conventional methods (blue: method 2, green: method 3, red: method 4) at height ranges of $10-15 \mathrm{~km}(10-15 \mathrm{~km})$ and $18-23 \mathrm{~km}(19-25 \mathrm{~km}) . N$ : number of profiles, $E_{\mathrm{t}}$ : total wave energy/unit mass $\mathrm{J} \mathrm{kg}^{-1}, E_{\mathrm{p}}$ : potential energy/unit mass $\mathrm{J} \mathrm{kg}^{-1}, E_{\mathrm{k}}$ : kinetic energy/unit mass $\mathrm{J} \mathrm{kg}^{-1}$, Det: standard deviation of $E_{\mathrm{t}}$, Phi: direction of horizontal wave propagation $\left({ }^{\circ}\right)$, clockwise from north, $F_{\mathrm{up}}$ : Fraction of upward wave-energy, AXR: axis ratio (intrinsic freq./inertial freq.), $T$ : period (day), $L_{\mathrm{V}}$ : vertical wavelength $(\mathrm{km}), L_{\mathrm{h}}$ : horizontal wavelength $(\mathrm{km})$. Height is expressed in $\mathrm{km}$.

\begin{tabular}{lcccccccccccc}
\hline Location & Height & $N$ & $E_{\mathrm{t}}$ & Det & $E_{\mathrm{p}}$ & $E_{\mathrm{k}}$ & Phi & $F_{\text {up }}$ & AXR & $T$ & $L_{\mathrm{V}}$ & $L_{\mathrm{h}}$ \\
\hline \multirow{2}{*}{ Tromelin } & $10-15$ & 23 & 4.1 & 1.0 & 0.3 & 3.8 & 57. & 0.64 & 1.28 & 1.46 & $2.6(1)$ & $1800(730)$ \\
& $18-23$ & 17 & 11.1 & 2.2 & 4.9 & 6.1 & 63. & 0.74 & 1.9 & 1.57 & $2.6(1)$ & $2200(890)$ \\
\hline \multirow{2}{*}{ Mahe } & $10-15$ & 27 & 5.6 & 1.3 & 0.5 & 5.1 & 76. & 0.60 & 2.29 & 2.69 & $2.6(1.3)$ & $2200(1100)$ \\
& $19-25$ & 9 & 29.7 & 6.9 & 8.5 & 21.1 & 58. & 0.70 & 3.44 & 1.79 & $2(0.76)$ & $1100(430)$ \\
\hline
\end{tabular}

Table 2. Same as Table 1 but during 15-26 January 2002 in TC Dina period (grey) and outside of TC Dina period (white).

\begin{tabular}{lcccccccccc}
\hline Location & Height & $E_{\mathrm{t}}$ & $E_{\mathrm{p}}$ & $E_{\mathrm{k}}$ & $\mathrm{Phi}$ & $F_{\mathrm{up}}$ & $\mathrm{AXR}$ & $T$ & $L_{\mathrm{v}}$ & $L_{\mathrm{h}}$ \\
\hline Tromelin & $10-15$ & 3.2 & 0.3 & 2.9 & 2 & 0.64 & 1.18 & 1.59 & $1.7(1)$ & $1400(850)$ \\
& & 4.9 & 0.3 & 4.5 & 106 & 0.64 & 3 & 0.61 & 2.6 & 460 \\
& $18-23$ & 13.1 & 4.7 & 8.4 & 98 & 0.77 & 1.26 & 1.49 & $2.6(1.3)$ & $1900(960)$ \\
& & 9.0 & 4.9 & 4.1 & 5 & 0.69 & 1.82 & 1.03 & $1.7(1)$ & $640(380)$ \\
\hline \multirow{2}{*}{ Mahe } & $10-15$ & 4.8 & 0.3 & 4.4 & 62 & 0.49 & 4.49 & 1.37 & 2.6 & 990 \\
& & 6.1 & 0.6 & 5.5 & 78 & 0.65 & 2.2 & 2.78 & $2.6(1.3)$ & $2200(1100)$ \\
& $19-25$ & 32.7 & 9.2 & 23.1 & 59 & 0.68 & 3.75 & 1.64 & 0.87 & 460 \\
& & 26.6 & 7 & 18.7 & 58 & 0.71 & 3.21 & 1.92 & $2(0.68)$ & $1200(150)$ \\
\hline
\end{tabular}

is quite consistent with the spectral index value $p$ of $5 / 3$ of the intrinsic spectrum. For the two sites, comparison between Phi values in the UT/LS suggests no filtering of GWs in the UT by the background wind in January.

The dataset is now examined during the period of TC Dina and outside the period. Table 2 supports that total energy density values are more important in the LS during TC Dina than in the UT. Conversely, GW energy densities decrease in the UT. On the whole, large values of $F_{\text {up }}$ in the LS indicate that GWs are produced in the troposphere except above Mahe during TC Dina for which GW source might be located at heights 15 and $19 \mathrm{~km}$ near the tropopause. When TC Dina is present, total energy density is $45 \%$ and $20 \%$ larger in the LS above Tromelin and Seychelles, respectively, with large values of kinetic energy density. Increased upward propagating wave energy is observed in the LS during TC Dina above Tromelin. Mean horizontal wave propagation is northward and eastward in the UT and LS respectively during TC Dina above Tromelin as opposed to observations outside the period of TC Dina. Conversely, values of horizontal propagation above Mahe are consistent during the two periods with those of Table 1. GWs with periods of 1.4-1.6 days and vertical wavelengths of $1-2.6 \mathrm{~km}$ are present above the 2 sites during TC Dina. The ratio $E_{\mathrm{k}} / E_{\mathrm{p}}$ is close to the spectral index value $p$ of $5 / 3$ in the LS above Tromelin during TC Dina as opposed to that outside the period of TC Dina. The ratio is equal to 2.5-2.6 in the LS above Mahe independently of the period. Horizontal wavelengths range between $400-$ $1900 \mathrm{~km}$ in the UT/LS above Tromelin with longer waves during the period of TC Dina in the LS and between 150$2200 \mathrm{~km}$ above Mahe with longer waves outside the period of TC Dina. Thus, observations of mean values of GW parameters suggest a significant and direct influence of TC Dina in GW activity above Tromelin as TC Dina intensifies and moves away southward to La Réunion (Fig. 1).

Table 3 gathers GW parameters derived from the wavelet method during 15-26 January during the period of TC Dina above Tromelin. GWs have $1-3 \mathrm{~km}$ vertical wavelengths, short horizontal wavelengths of $100-500 \mathrm{~km}$ in the UT, long horizontal wavelengths of $140-2000 \mathrm{~km}$ in the LS and periods of $7 \mathrm{~h}-1.8$ days above Tromelin. GWs have consistent spectral characteristics with those reported during TC Hudah (Chane Ming et al., 2002). Horizontal wave propagation is mostly northward in the UT and south-westward in the LS during 19-23 January.

Finally results from conventional and wavelet analyses are well-consistent on the spectral characteristics except for the horizontal wave propagation. Besides Phi is a highly derived parameter also depending on assumptions of applied method of analysis, conventional method provides a mean value of 
Table 3. GW parameters above Tromelin during 15-26 January 2002 using wavelet analysis (method 5) at 10-15 km heights and 18-22 km heights.

\begin{tabular}{|c|c|c|c|c|c|c|c|c|c|c|}
\hline \multirow[b]{2}{*}{ Date } & \multirow[b]{2}{*}{ Phi } & \multicolumn{4}{|c|}{ Parameters: $10-15 \mathrm{~km}$} & \multicolumn{4}{|c|}{ Parameters: $18-22 \mathrm{~km}$} & \multirow[b]{2}{*}{$L_{\mathrm{h}}$} \\
\hline & & AXR & $T$ & $L_{\mathrm{V}}$ & $L_{\mathrm{h}}$ & Phi & AXR & $T$ & $L_{\mathrm{V}}$ & \\
\hline 020115 & 70,310 & $1.2,1.5$ & $0.8,1.5$ & $1,2.8$ & 450 & 270 & 2.5 & $0.8,1.8$ & $1,2.8$ & 400,1000 \\
\hline 020116 & 330 & 1.1 & 0.6 & 2.7 & 300 & 80,260 & $1.1,1.7$ & $1,1.6$ & 2.7 & 300,1400 \\
\hline 020117 & 280 & 1.2 & 1.4 & 2.2 & $100-500$ & 230 & 1.4 & $0.3,1.4$ & 2.2 & 200,500 \\
\hline 020118 & 20,60 & 1.2 & $0.35,1.2$ & 2.2 & $100-250$ & 250 & $0.6,1.1$ & $1.1,1.5$ & 2.5 & 700,1200 \\
\hline 020119 & 75 & 1.1 & $0.3-1.6$ & 3 & 150 & 250 & 1.6 & $1.1,1.7$ & 3 & 1500,2200 \\
\hline 020120 & 50 & 1.4 & $0.8,1.4$ & 2 & 230 & $210-250$ & 1.1 & $1.2-1.6$ & 2 & 1500 \\
\hline 020121 & 300 & $1.2,1.8$ & $0.6,1.4$ & $2.2,3$ & $200-350$ & 240 & 1.2 & $0.8-1.5$ & $1.5,3$ & $900-1500$ \\
\hline 020123 & 340 & $1.2,1.8$ & 1 & 2.2 & $150-400$ & 80,105 & $1.2,2$ & 0.6 & 2.4 & $700-1100$ \\
\hline 020124 & 20,320 & 1.2 & $0.8,1.4$ & 1.5 & 150,450 & 220 & $1.1,2$ & $0.3,1.4$ & 1.8 & $150-350$ \\
\hline 020125 & 75 & 1.1 & 1.6 & $1,2.2$ & $100-300$ & 280 & 2.2 & $0.6,1.6$ & 2.4 & $200-600$ \\
\hline 020126 & 300 & $1.1,2,2.7$ & $0.6,1.4$ & $1.2,2.2$ & 200 & 170 & $1.2,1.8$ & 0.8 & $1.5,2.5$ & 320 \\
\hline
\end{tabular}

Phi whereas the wavelet method shows that Phi daily varies during the evolution of TC Dina. Indeed the wavelet method analyzes the dominant horizontal direction of wave propagation from individual vertical profiles.

\subsubsection{Link between GW and convective activities}

Two localized active regions of deep convection are visualized on daily maps of National Oceanographic and Atmospheric Administration (NOAA) OLR during the period of TC Dina in the South-West Indian basin: a first convective region over Africa at longitudes between $20^{\circ}$ and $40^{\circ}$ east and at latitudes between $0^{\circ}$ and $15^{\circ}$ south and a second one covering the SWIO at longitudes between $50^{\circ}$ and $80^{\circ}$ east and at latitudes between $0^{\circ}$ and $10^{\circ}$ south from where TC Dina is originated (Fig. 7a). Moreover, convective activity varies with time from 17 to 28 January such as the intensity, the size and the location. Convective areas are merged outside the period of TC Dina (Fig. 7a and d) and distinct during the period of TC Dina (Fig. 7b and c). In addition, they are both active during the first stages of TC Dina from 17 to 22 January 2002 at longitudes between $20^{\circ}$ and $70^{\circ}$ east.

Averaged total energy density over 2 successive radiosonde profiles provides a guide for understanding GW variability in relation with daily activity of convection. During the TC period, averaged total energy density continuously increases from $8.4 \mathrm{~J} \mathrm{~kg}^{-1}$ on $15-16$ January to $17.8 \mathrm{~J} \mathrm{~kg}^{-1}$ on $20-21$ January and then decreases to $8.6 \mathrm{~J} \mathrm{~kg}^{-1}$ on $28-29$ January at heights of $18-23 \mathrm{~km}$ at Tromelin (Fig. 8a). The peak value corresponds to $30-40 \%$ of the climatological value observed in the LS in austral summer above Tromelin from 1998 to 2003 (Chane Ming et al., 2007). Moreover, $E_{\mathrm{p}}$ and $E_{\mathrm{k}}$ energy densities peak on 20-21 January in the LS when the maximum surface wind speed (MWS) is maximum. Note that the first peak is mainly caused by a strong variation of potential energy density whereas the second one is mainly resulted from the variation of kinetic energy density on 23 January after the passage of TC Dina near La Reunion. The two peaks have similar magnitudes in kinetic energy. Furthermore, the MWS can be well estimated from total energy density using a linear regression. Correlation coefficient is 0.94 for MWS ranging between 25 and $60 \mathrm{~m} \mathrm{~s}^{-1}$. Time evolution of $F_{\text {up }}$ is investigated using the conventional techniques (Fig. 8b). $F_{\text {up }}$ increases from 17 to 23 January in the LS with a steady maximum of 0.85 from 19 to 23 January. At the same time, it decreases in the UT from 0.75 on 19 January to 0.44 on 22 January and increases to 0.75 from 25 January. Observation of $F_{\text {up }}<50 \%$ suggests that GWs with downward energy are dominant in the UT from 21 to 24 January. Thus, as Fig. 6c, dominant GW sources are localized between $15 \mathrm{~km}$ and the tropopause height during the strong activity of TC Dina and at heights below $10-\mathrm{km}$ outside the period.

GW energy density in the LS above Tromelin is now examined in relation with the convective activity over Tromelin, Mahe, the west and north basins (Fig. 8c). Time evolution of GW energy density is well-correlated with OLR data above Tromelin with minimum values of $200 \mathrm{~W} \mathrm{~m}^{-2}$ during 20 and 22 January when Tromelin is under the cloud shield of TC Dina (Fig. 7b). Although variation of OLR data above Mahe is quite consistent with that above Tromelin, convection is more intense and highly modulated by mixed equatorial waves (Chane Ming et al., 2007). A 4-5 day modulation is clearly observed above the two sites in January. Strong convection is also observed above Mahe at the time when the cloud shield of TC Dina covers Tomelin. Convective activities over the west and north basins are anticorrelated from 2 January to 21 January and correlated after 21 January. They are both active from 20 to 22 January when OLR minima of about $180 \mathrm{~W} \mathrm{~m}^{-2}$ are observed above Tromelin. Finally, the activity over Tromelin during TC Dina is correlated with that over the north basin. A 7-8 

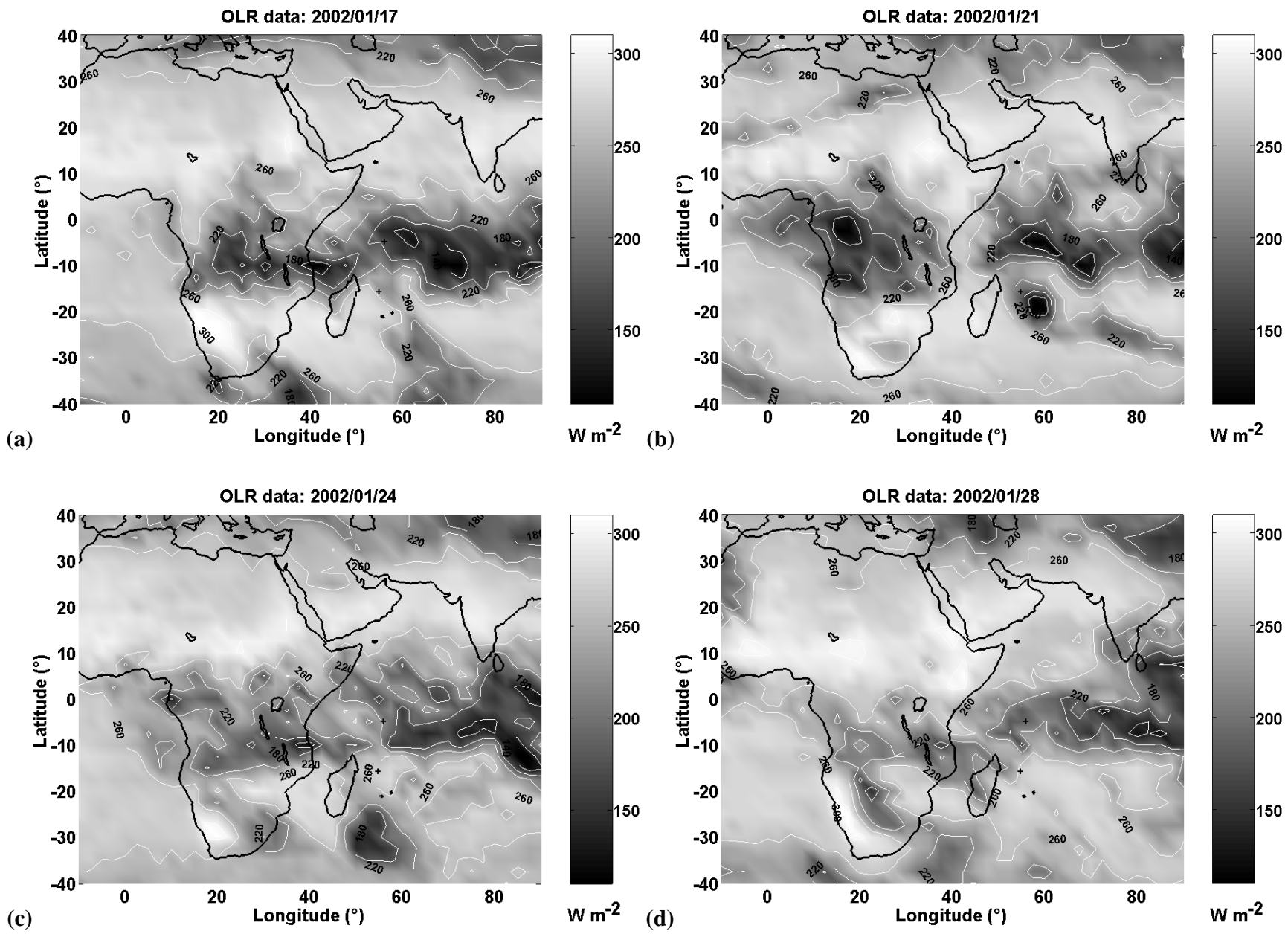

Fig. 7. Maps of $2.5^{\circ}-2.5^{\circ}$ gridded NOAA Interpolated Outgoing Longwave Radiation (OLR) at longitudes between $-10^{\circ} \mathrm{W}$ and $90^{\circ} \mathrm{E}$ and at latitudes between $40^{\circ} \mathrm{N}$ and $-40^{\circ} \mathrm{S}$ : on (a) 17 January, (b) 21 January, (c) 24 January and (d) 28 January 2002.

day modulation of convective activities is clearly dominant above the two basins.

\subsection{Case of TC Faxai}

In this second case, only combined conventional analyses are applied on vertical profiles of temperature and horizontal winds at height ranges of $10-16 \mathrm{~km}$ and $19-25 \mathrm{~km}$ in December 2001 to characterize GWs above Guam during four different periods: before the birth of TC Faxai from 1 to 10 December, during the tropical storm from 11 to 20 December, during the TC from 21 to 25 December and at the death of the TC from 26 to 31 December 2001 (hereinafter noted periods 1, 2, 3 and 4).

\subsubsection{Characteristics of GWs}

Wind hodographs show clear evidence of elliptical structures with characteristics of GW in the UT and LS during December 2001. Associated normalized frequencies vary between
1.1 and 2.45 with periods between 0.87 and 2.13 days. Histograms of normalized intrinsic frequencies, obtained from $5 \mathrm{~km}$-running mean axis ratio profiles, peak at $1.5-2$ (periods between 1 and 1.43 days) independently of the studied periods. Table 4 provides insight into GW characteristics computed with combined conventional analyses during each period. Globally, a decrease in total energy density is revealed in the UT vice versa in the LS with a peak during period 3. Total energy density is correlated with potential and kinetic energy densities during periods 2, 3 and 4 in the UT while an anti-correlation with kinetic energy density is observed in the LS during the whole period. Moreover, total energy density in the UT is dominantly kinetic and correlated with those calculated for the LS althougth the monthly linear trends are anti-correlated. Note that the sum of total energy densities in the UT and the LS varies between 16 and $18 \mathrm{~J} \mathrm{~kg}^{-1}$ during the 4 periods and the ratio $E_{\mathrm{k}} / E_{\mathrm{p}}$ in the LS varies between 0.8 and 1.6 with values of 0.8 during period 3 and about $5 / 3$ during period 4 . Direction of horizontal propagation is 
Table 4. Same as Table 1 but for TC Faxai at height ranges of $10-16 \mathrm{~km}$ and $19-25 \mathrm{~km}$ at several periods: $1-$ before the birth of TC (1-10 December 2001), 2 - during the tropical storm (11-20 December 2001), 3 - during the tropical cyclone (21-25 December 2001) and 4 - at the death of the tropical cyclone (26-31 December 2001).

\begin{tabular}{cccccccccccc}
\hline Height & Time & $N$ & $E_{\mathrm{t}}$ & $E_{\mathrm{p}}$ & $E_{\mathrm{k}}$ & Phi & $F_{\text {up }}$ & AXR & $T$ & $L_{\mathrm{V}}$ & $L_{\mathrm{h}}$ \\
\hline \multirow{2}{*}{$10-16$} & 1 & 18 & 4.6 & 0.3 & 4.3 & 334 & 0.53 & 3.59 & 0.61 & $3.1(1.5)$ & $550(270)$ \\
& 2 & 18 & 3.4 & 0.3 & 3.1 & 136 & 0.46 & 8.66 & 0.25 & 3.1 & 270 \\
& 3 & 11 & 3.9 & 0.4 & 3.6 & 184 & 0.44 & 2.17 & 1 & 3.1 & 960 \\
& 4 & 7 & 1.7 & 0.2 & 1.5 & 155 & 0.52 & 6.56 & 0.33 & 3.1 & 280 \\
\hline \multirow{2}{*}{$19-25$} & 1 & 14 & 13.5 & 7.4 & 6.1 & 144 & 0.75 & 1.66 & 1.31 & $3.1(1.5,1)$ & $1500(740,490)$ \\
& 2 & 16 & 13 & 6.1 & 6.9 & 123 & 0.76 & 1.1 & 1.97 & $3.1(1)$ & $4300(1400)$ \\
& 3 & 8 & 14.8 & 8.2 & 6.6 & 165 & 0.77 & 1.4 & 1.55 & $3.1(1)$ & $2000(580)$ \\
& 4 & 7 & 14.2 & 5.3 & 8.7 & 94 & 0.76 & 1.04 & 2.09 & $3.1(1.2)$ & $6900(2700)$ \\
\hline
\end{tabular}

south-eastward in the UT/LS during periods 2 and 3 while horizontal winds are north-westward in the UT and westward in the LS. QBO eastward winds are also observed above $25 \mathrm{~km}$ height. As for $F_{\text {up }}$, it slightly increases from $75 \%$ to $77 \%$ in the LS and decreases from 53\% to $44 \%$ during periods 2 and 3 in the UT suggesting that GW sources are located at heights between 10-km height and the tropopause during TC Faxai. By and large, GWs have periods of $6-15 \mathrm{~h}$ during periods 1, 2 and 4 and about 1 day during period 3 in the UT. Periods vary between 1.3 and 2.1 days in the LS. Modes with vertical wavelengths of $1-1.5 \mathrm{~km}$ and $3.1 \mathrm{~km}$ are observed in the UT and the LS with longer horizontal wavelengths (490 and $6900 \mathrm{~km}$ ) in the LS compared with observations in the UT (270-960 km). Small amount of GWs with large horizontal wavelengths were especially observed above Faxai during the decay stage of TC Faxai.

\subsubsection{Link between GW and convective activities}

The convective activity is investigated above the region at longitudes between $100^{\circ} \mathrm{E}$ and $177.5^{\circ} \mathrm{E}$ and at latitudes between $40^{\circ} \mathrm{S}$ and $40^{\circ} \mathrm{N}$ on daily maps of OLR in December. They reveal strong convection centered near the equator at latitudes between $-15^{\circ}$ and $15^{\circ}$ above the Indonesian region during from 1 and 10 December (Fig. 9a). It progressively moves to west at longitudes between $160^{\circ}$ and $177^{\circ} \mathrm{E}$ from 11 to 19 December (Fig. 9b). On 19 December, TC Faxai results from the convective pattern and moves north-westward from latitude of $9^{\circ} \mathrm{N}$ toward Guam as the convective pattern moves at east of $160^{\circ} \mathrm{E}$ (Fig. 9c). As the TC is evacuated east-northward at mid-latitudes from 24 to 25 December, the activity of convection is reorganized. Convection continuously intensifies along the equator at latitudes between $10^{\circ} \mathrm{S}$ and $10^{\circ} \mathrm{N}$ and longitudes between 100 and $180^{\circ} \mathrm{E}$ (Fig. 9d). At the end, the maximum of the activity is located at north of Australia on 30 December.

To consider the link between GW and convective activities, daily evolution of energy densities are calculated from 2 successive radiosonde data at 00:00 UTC and 12:00 UTC in the UT and LS, respectively, from 1 to 30 December (Fig. 10a and b). Energy densities are correlated in the UT and total energy density is mainly made up of kinetic energy. It also reveals four distinct periods in the UT: period 1 from 1 to 15 December with large and highly variable total energy densities between $3 \mathrm{~J} \mathrm{~kg}^{-1}$ and $8 \mathrm{~J} \mathrm{~kg}^{-1}$, period 2 from 15 to 20 December with minimum values between $2 \mathrm{~J} \mathrm{~kg}^{-1}$ and $3 \mathrm{~J} \mathrm{~kg}^{-1}$, period 3 from 20 to 24 December with values $>3 \mathrm{~J} \mathrm{~kg}^{-1}$ peaking at $6 \mathrm{~J} \mathrm{~kg}^{-1}$ on 23 December and period 4 from 25 to 31 December with small energy densities varying between $1.5 \mathrm{~J} \mathrm{~kg}^{-1}$ and $2.5 \mathrm{~J} \mathrm{~kg}^{-1}$. In addition, Fig. $10 \mathrm{a}$ shows that the evolution of total energy density and the MWS of TC Faxai are well-correlated during period 3 with a correlation coefficient of 0.76 . Figure $10 \mathrm{~b}$ also suggests that total energy densities in the UT and the LS are also correlated but the evolution of patterns is delayed and stretched over time in the LS. The delay is $2-4$ days for potential energy density in the LS. Note that potential and kinetic energy densities are correlated during period 1 and anti-correlated during the other periods in the LS and the evolution of kinetic energy density is delayed 2-5 days compared with that of potential energy density. Potential energy density mainly controls variation of total energy density during period 1 and conversely by kinetic energy density during period 3 . Figure 10c gives insight of time evolution of $F_{\text {up }}$ in December 2001 in the UT/LS. It shows that $F_{\text {up }}$ oscillates around 50\% with periods of 3-4 days and 7 days in the UT during December which suggests that GW convective sources are alternately located at heights below $10 \mathrm{~km}$ and between 10 and the tropopause in relation with the intensity of convection. In particular values of $F_{\text {up }}$ in the UT reveal strong convection occuring between 5 and 8 December, 12 and 15 December and 22 and 23 December in the UT in agreement with intensity peaks of total energy density in the UT. Particularly deep convection is observed at the beginning of TC Faxai on 18 and 20 December and when TC becomes very intense on 22 December with a minimum of $F_{\text {up }} . F_{\text {up }}$ increases in the LS during TC Faxai from 21 to 25 December. 
(a)

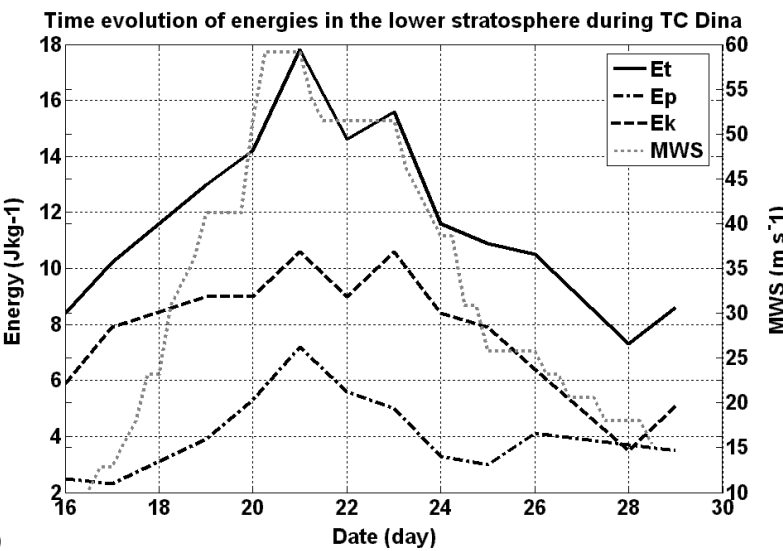

(b)
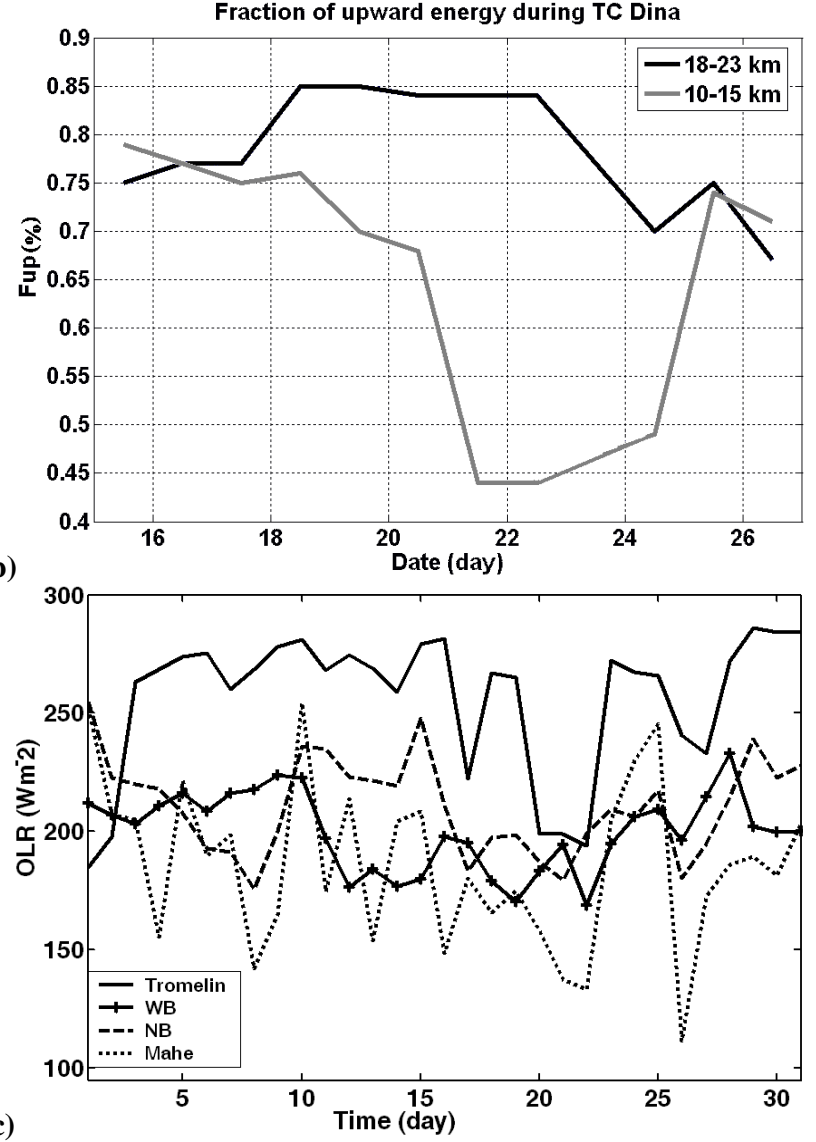

tinct convective structures above Guam and the signature of TC Faxai in late December in vicinity of Guam. The four convective structures propagate eastward from $100^{\circ} \mathrm{E}$ to the Date line during period 1. In addition, Fast Fourier Transform spectral density (FFT) applied on time series of MJO filtered OLR data reveals the presence of convective structures with periods of 3 days, 5-6 days and 13 days in the vicinity of Guam at longitudes between $135^{\circ} \mathrm{E}$ and $160^{\circ} \mathrm{E}$ (Fig. 11b). Continuous complex Morlet wavelet scalogram (Chane Ming et al., 1999) also confirms the presence of convective modes with periods of 3-4 days, 6-7 days and 13 days above Guam in December (Fig. 11c). Modes of 3-4 day periods are intense during period 1 with a maximum on 12 December. A 6-7 day mode is dominant during the period of TC Faxai from 15 to 25 December. Intensity peak of the 13-day convective mode occurs from 25 December to 15 January. In comparison the FFT reveals modulation of GW energy densities with periods of 3-4, 5-7, 9-10 days in the UT and 4, 7, 13 days in the LS. Figure 12 shows time series of averaged NOAA Interpolated OLR data above Guam island, in the vicinity of Guam within a radius of $12.5^{\circ}$, over the west basin, the east basin and the cloud shield of TC Faxai. On the whole, convective activity over the west basin and the east basin is anti-correlated during the first 3 periods and correlated during period 4 with a quite steady OLR value of about $195 \mathrm{~W} \mathrm{~m}^{-2}$. A reversal of the intensity of convection above the two basins occurs on 11 December. Finaly, Guam is under the influence of convection over the west basin until 17 December and that over the east basin more particularly over TC Faxai from 17 December to 24 December. The evolution of GW total energy density in the UT is also in agreement with convective activity above Guam within radius of $12.5^{\circ}$ and above TC Faxai from 16 to 25 December. Moreover, strong convective activities are observed on 2 December and from 6 to 10 December over the west basin and Guam, 12 December over the east basin, on 19 December over TC Faxai and on 23 December over Guam and TC Faxai. In conclusion, last results are well-consistent with variation of $F_{\text {up }}$ (Fig. 10c).

\section{Conclusions}

Fig. 8. Time evolution of (a) total, potential and kinetic energy densities and the maximum wind speed of TC Dina (MWS), (b) fraction of upward energy in the UT (10-15 km) and the LS (18-23 km) from 16 to 29 January 2002 and (c) Time series of OLR over Tromelin $\left(2.5^{\circ}\right.$ radius), Mahe $\left(2.5^{\circ}\right.$ radius $)$, the west part of the basin $\left(25^{\circ}-35^{\circ} \mathrm{E}, 0^{\circ}-15^{\circ} \mathrm{S}\right)$ and the north part of the basin $\left(50^{\circ}-\right.$ $\left.60^{\circ} \mathrm{E}, 0^{\circ}-10^{\circ} \mathrm{S}\right)$.

To provide insight into multi-scale convective patterns, the Hovmöller diagram of $2.5^{\circ}-2.5^{\circ}$ gridded NOAA Interpolated MJO filtered OLR data averaged over latitudes between $0^{\circ} \mathrm{N}$ and $20^{\circ} \mathrm{N}$ is pictured (Fig. 11a). It shows evidence of 4 dis-

GW signatures in the UT/LS, during the evolution of two intense TCs, were extracted by using the GPS windsonde profiles with high vertical resolution. One of the TCs is the TC Dina in January 2002 in the SWIO, the other one is TC Faxai in December 2001 in the NWPac. The sounding profiles used in Dina case were launched twice daily and daily at the SWIO islands of Mahe and Tromelin, respectively. In Faxai case, twice daily profiles were used at Guam in the NWPac. Combined-conventional method and wavelet analysis method were used to derive the wave energy, e.g., the total, kinetic, and potential energy densities, and to retrieve wave parameters such as frequency, the wavelength both in 

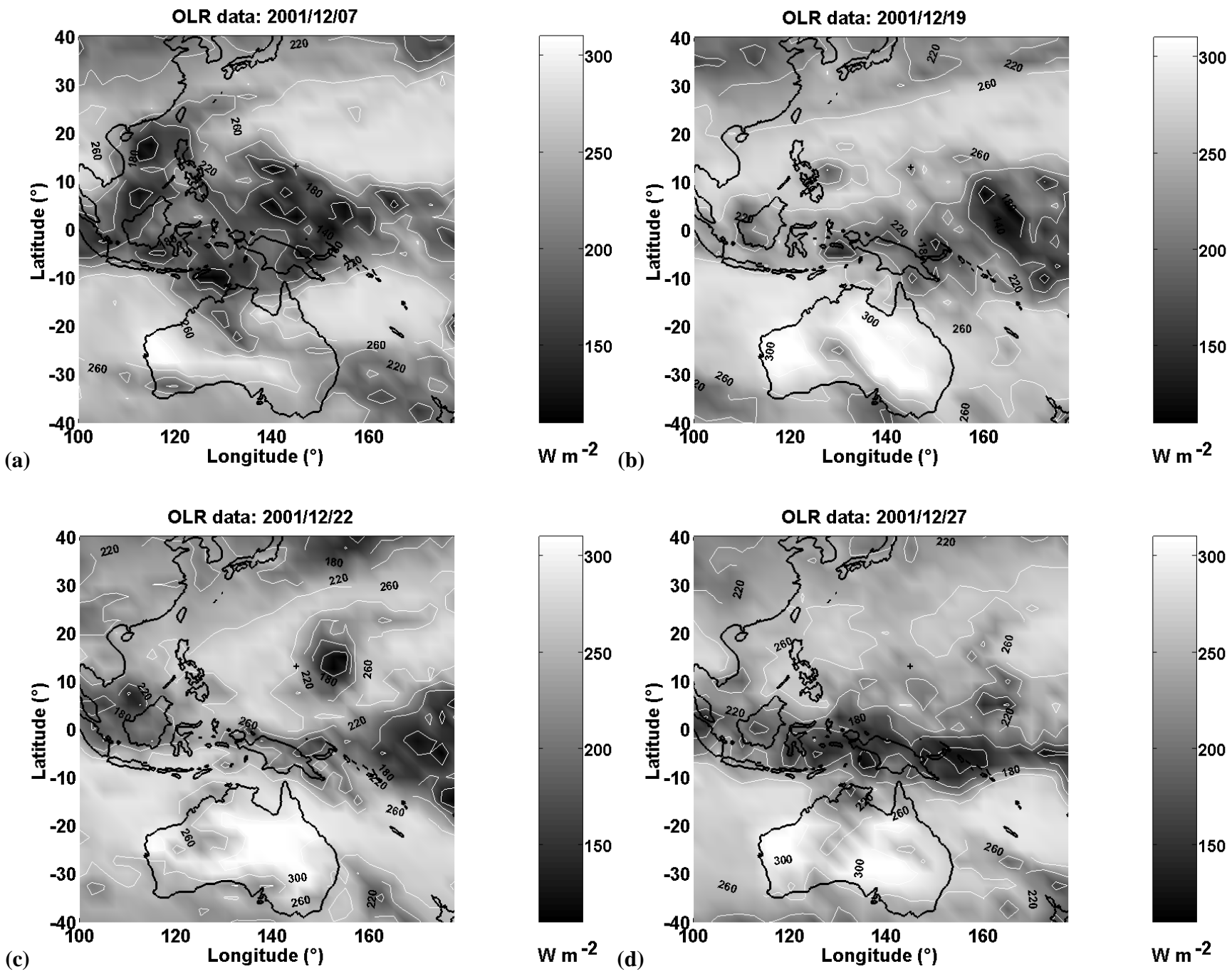

Fig. 9. Daily maps of $2.5^{\circ}-2.5^{\circ}$ gridded NOAA Interpolated Outgoing Longwave Radiation (OLR) at longitudes between $100^{\circ} \mathrm{E}$ and $177.5^{\circ} \mathrm{E}$ and at latitudes between $40^{\circ} \mathrm{S}$ and $40^{\circ} \mathrm{N}$ on (a) 7 December, (b) 19 December, (c) 22 December and (d) $27 \mathrm{December} 2001$.

the horizontal and the vertical, and propagation direction. The investigation results showed that GWs are generally observed in the two ocean basins with periods spanning over $6 \mathrm{~h}$ to 2.5 day, vertical wavelenghts of $1-3 \mathrm{~km}$, horizontal wavelengths of $<2000 \mathrm{~km}$ in the UT and $>2200 \mathrm{~km}$ in the LS. Indeed, present analyses focused on slow GWs with short vertical wavelengths due to the limitations of the radiosonde technique and the vertical height ranges in the UT/LS (Alexander and Barnet, 2007). Several studies based on observations and numerical simulations also revealed the importance of fast GWs with longer vertical wavelengths of 6-11 km in the GW signal in the vicinity of TCs (Dhaka et al., 2003; Chun et al., 2007; Kuester et al., 2008).

The association of GWs to TCs were disclosed by the estimation results, that is reflected by the substantial enhancement in GW total energy density as the TCs are near the observation sites. Particularly, these waves were associated with a vertical wavelength of $2 \mathrm{~km}$ and a period of 2 days. Moreover, horizontal direction of wave propagation was eastward and equatorward during the peak intensity of TC and recurve whereas the background wind was westward in the UT. This also suggests an energetic contribution of TCs to the westerly phase of the QBO above 25-km height (Maruyama, 1994; Shimizu and Tsuda, 2001).

Case study of TC Dina also highligthed consistencies in results in regards to applied methods during the evolution of TC. In comparison with conventional analyses, wavelet method detailed the daily spectral characteristics of GWs. The contribution to total energy density produced by TC Dina was noteworthy above Mahe and Tromelin. However GW activity above Mahe is less affected by TC Dina because of the distance from the TC and its location in the equatorial 
(a)
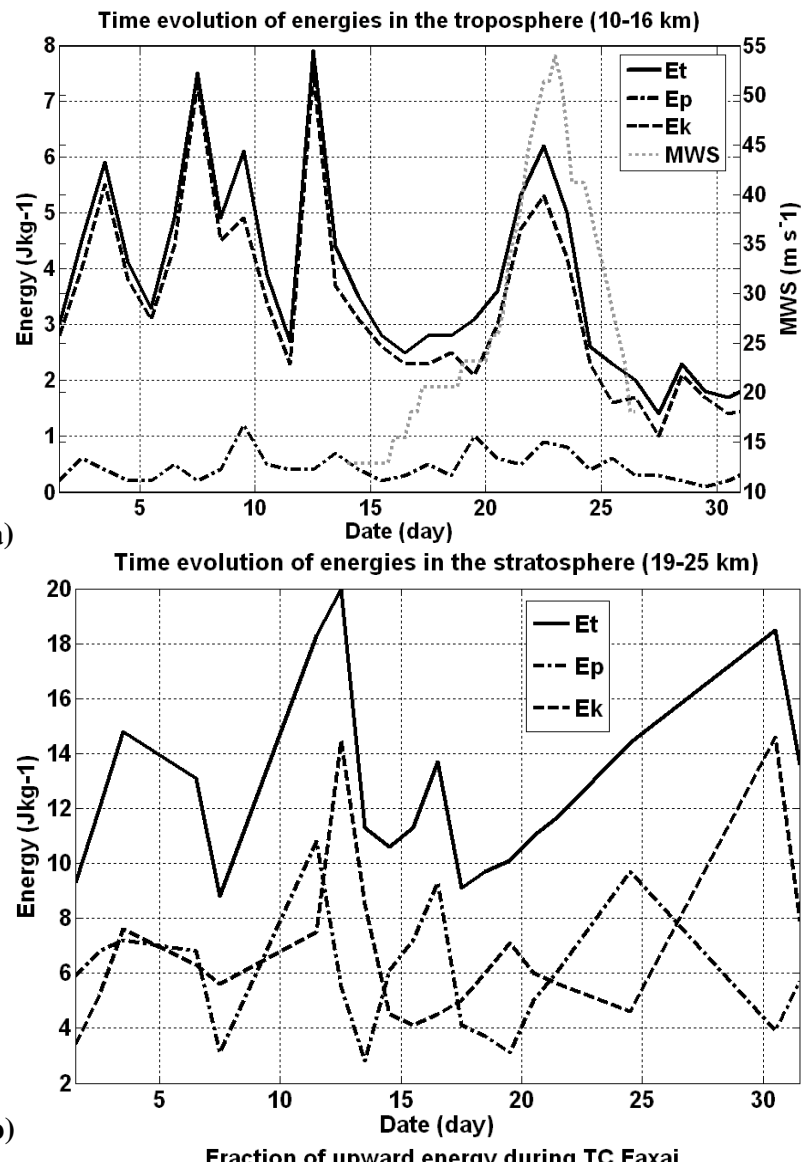

(b)

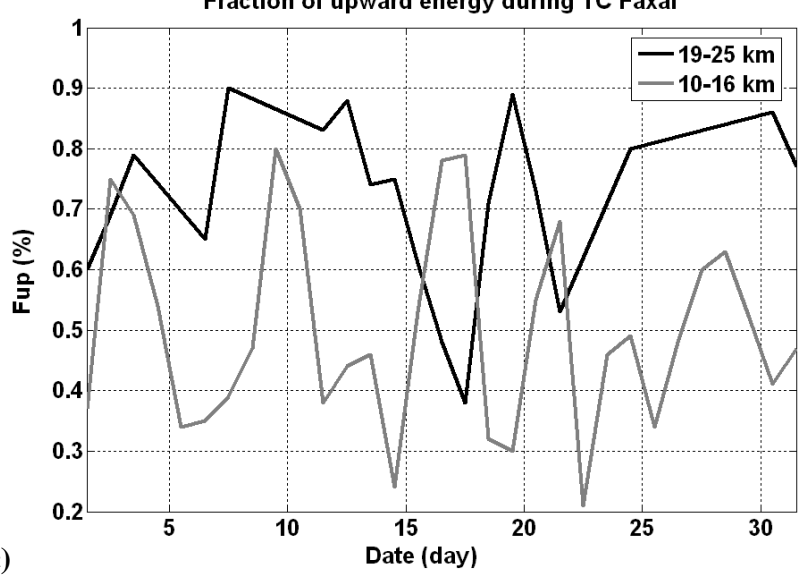

Fig. 10. Daily evolution of total, potential and kinetic energies from 2 successive radiosonde data 00:00 UT and 12:00 UT in (a) the UT and (b) the LS and (c) the corresponding fraction of upward energy. The maximum surface wind of TC Faxai is plotted (dotted grey line on Fig. 10a).

region controlled by continuous strong convection and active mixed equatorial waves. An increase in total energy density of $45 \%$ in total energy density was estimated in the LS above Tromelin and corresponds to about $30 \%$ of the climatological energy density in austral summer (Chane-Ming et al.,

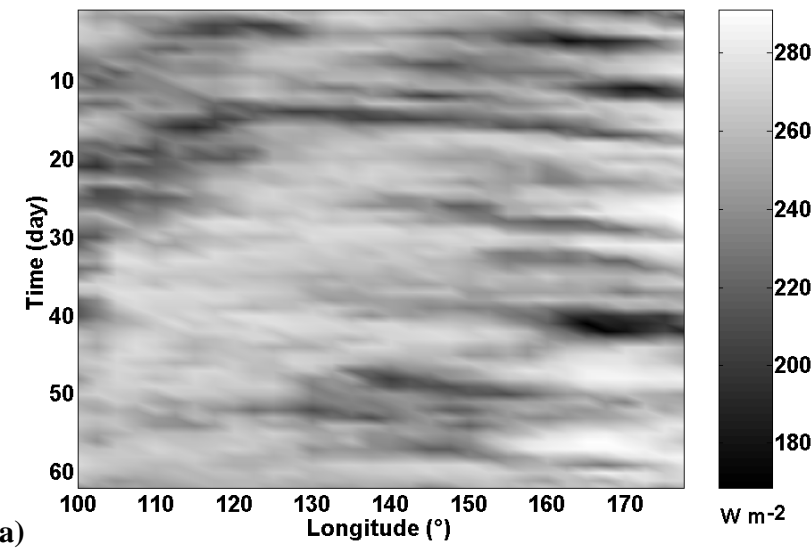

(b)
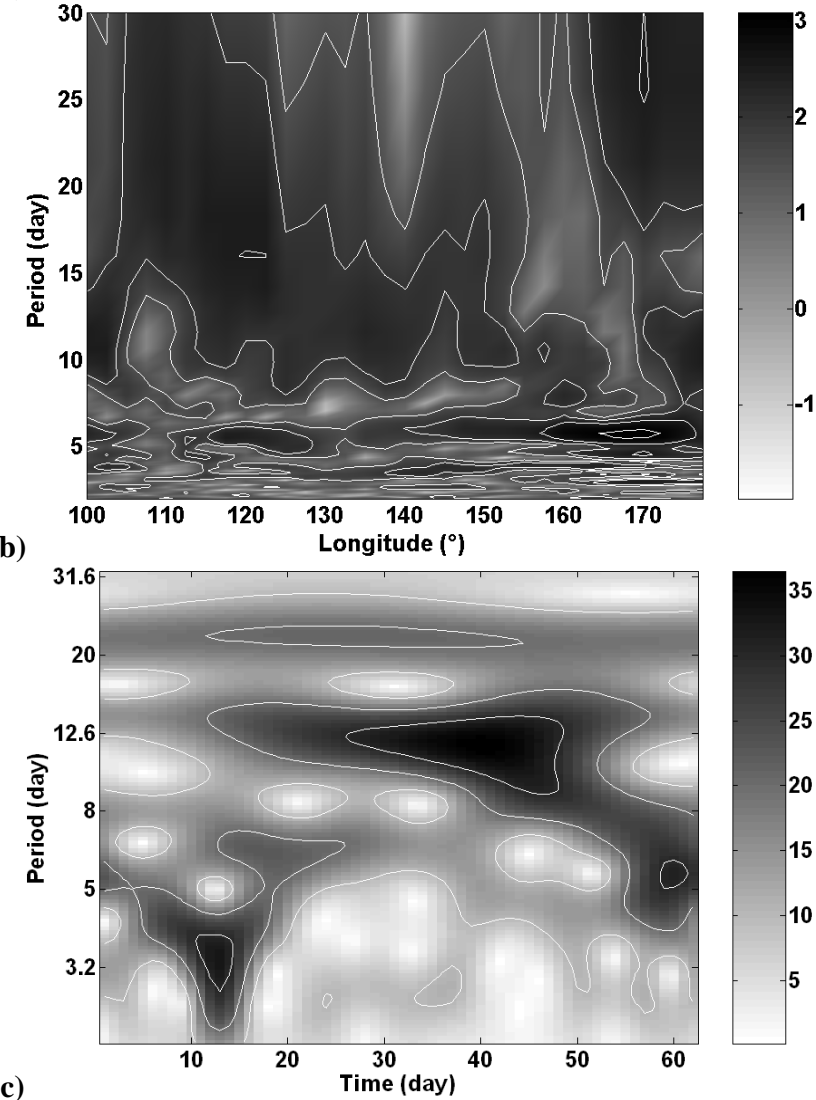

Fig. 11. (a) Hovmöller diagram (time versus longitude) of $2.5^{\circ}-$ $2.5^{\circ}$ gridded NOAA Interpolated MJO filtered OLR data averaged over latitudes between $0^{\circ} \mathrm{N}$ and $20^{\circ} \mathrm{N}$ for longitudes between $100^{\circ} \mathrm{E}$ and $177.5^{\circ} \mathrm{E}$ and from 1 December 2001 to 31 January 2002, (b) Period-longitude distribution of Fast Fourier Transform spectral density in base-10 logarithmic scale and (c) Period-time diagram of modulous of continuous complex Morlet transform coefficients ( 5 octaves and 30 voices). OLR data is filtered by using a fourth-order polynomial fit.

2007). In addition, activity of total energy density in the LS above Tromelin was highly correlated with convective activity above the site as well as with that over the north basin from where TC Dina was originated. 


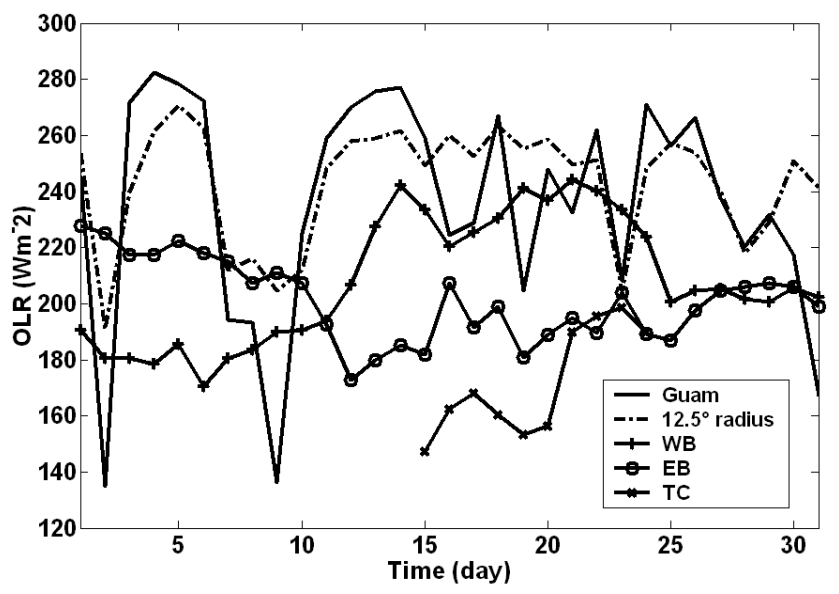

Fig. 12. Time series of NOAA Interpolated OLR data above (a) Guam island $\left(2.5^{\circ}\right.$ radius $)$, (b) in the vicinity $\left(12.5^{\circ}\right.$ radius $)$, (c) the west basin at longitudes between $110^{\circ} \mathrm{E}$ and $140^{\circ} \mathrm{E}$ and latitudes between $10^{\circ} \mathrm{S}$ and $10^{\circ} \mathrm{N}$, (d) the east basin at longitudes between $155^{\circ} \mathrm{E}$ and $180^{\circ} \mathrm{E}$ and latitudes between $10^{\circ} \mathrm{S}$ and $10^{\circ} \mathrm{N}$ and (e) TC Faxai $\left(10.5^{\circ}\right.$ radius $)$.

Case study of TC Faxai showed evidence of 4 distinct periods in GW activity in the UT: before the formation of TC Faxai with high variable and large total energy density controlled by deep convection and mixed equatorial waves, at the birth of TC Faxai when total energy was steady, when Faxai was a TC for which total energy density increased as function of the intensity of the TC and finally during the death of Faxai with steady lower values of total energy density. Variation of mean energy density was well-correlated in the UT/LS in contrast with the anti-correlation observed in the linear trends as previouly discussed in Chane Ming et al. (2007). The evolution of GW total energy density in the UT was also in agreement with convective activity above Guam and above Faxai during tropical storm and TC stages.

Moreover, modulation of convective activities was observed by combining the GW analysis results and the OLR, a NOAA product reflecting the tropical convective activities. The investigation results for the two basins showed that the GW activity is modulated by tropical convective activity of 4 days and 7-8 days. It is anticipated that the feature is associated with the influence of the mixed equatorial waves (Wheeler and Kiladis, 1999). In addition, Hövmöller diagram, spectral analyses of convective activity and energy densities also revealed a wave-modulation of GW activity in the UT/LS with periods of 10-13 days in the NWPac. When TCs were intense, GW sources were near the tropopause in the UT otherwise the location varied in the troposphere as a function the strength of convection modulated by mixed equatorial waves especially in the NWPac.

Based on TOGA COARE datasets, GWs with quasi-2-day period, short vertical wavelengths of $2-5 \mathrm{~km}$ and long horizontal wavelengths of $1000-6100 \mathrm{~km}$ have been described above the equatorial and tropical Pacific Ocean in relation with the convective activity (Karoly et al., 1996; Takayabu et al., 1996; Wada et al., 1999). In addition, Pires et al. (1997) examined Kelvin waves of 7-10 days and mixed Rossby gravity-waves of 3-6 days with horizontal wavelengths ranged between 3000 and $6500 \mathrm{~km}$. Similar GWs with long horizonal wavelengths were also reported above the Indonesian maritime continent (Shimizu and Tsuda, 1997). Nevertheless, since horizontal wavelength is a highlyderived parameter we should be cautious about the presence of GWs with long horizontal wavelengths $>2000 \mathrm{~km}$.

Recently, radiosonde observations of winds and temperature over several sites in Southeast Asia during the CPEA campaign confirmed the presence of a convective Kelvin waves with periods of 7-days in the UT/LS (Sridharan et al., 2006) and of 10-12 days in the LS (Tsuda et al., 2006). Among convectively coupled equatorial waves, mixed Rossby gravity-waves with periods of 3-4 days also revealed to be dominant in the equatorial region (Wheeler and Kalidis, 1999).

Acknowledgements. The French team is financially supported by the French LEFE-IDAO program from the Institut National des Sciences de l'Univers of Centre National de la Recherche Scientifique and La Région Réunion/L'Europe. Zeyu Chen is co-supported by a funding from the Chinese Academy of Sciences with Number KZCX2-YW-123, and a funding from the National Science Foundation of China with Number 40333034. The authors thank Météo-France, the Wyoming University for windsonde data and the Physical Sciences Division of the Earth System Research Laboratory for the NOAA OLR dataset.

Topical Editor F. D'Andrea thanks two anonymous referees for their help in evaluating this paper.

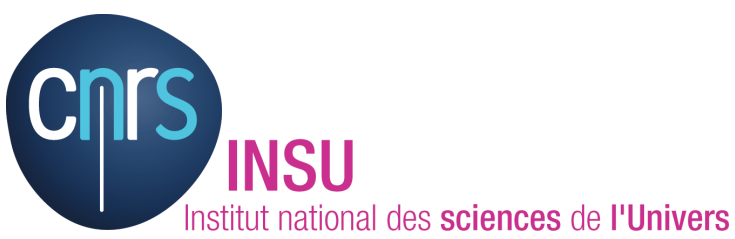

The publication of this article is financed by CNRS-INSU.

\section{References}

Allen, S. J. and Vincent, R. A.: Gravity wave activity in the lower atmosphere: Seasonal and latitudinal variations, J. Geophys. Res., 100(D1), 1327-1350, 1995.

Alexander, M. J. and Barnet, C.: Using satellite observations to constrain parameterizations of gravity wave effects for global models, J. Atmos. Sci., 64, 1652-1665, 2007.

Cairo, F., Buontempo, C., MacKenzie, A. R., Schiller, C., Volk, C. M., Adriani, A., Mitev, V., Matthey, R., Di Donfrancesco, G., Oulanovsky, A., Ravegnani, F., Yushkov, V., Snels, M., Cagnazzo, C., and Stefanutti, L.: Morphology of the tropopause layer and lower stratosphere above a tropical cyclone: a case study on cyclone Davina (1999), Atmos. Chem. Phys., 8, 3411- 
3426, 2008,

http://www.atmos-chem-phys.net/8/3411/2008/.

Chane Ming, F., Molinaro, F., and Leveau, J.: Wavelet techniques applied to lidar signal in the analysis of the middle atmosphere dynamics, Appl. Sig. Process., 6(2), 95-106, 1999.

Chane Ming, F., Roff, G., Robert, L., and Leveau, J.: Gravity wave characteristics over Tromelin island during the passage of cyclone Hudah, Geophys. Res. Lett., 29(6), 1094, doi:10.1029/21001GL013286, 2002.

Chane Ming, F., Guest, F. M., and Karoly, D.: Gravity waves observed in temperature, wind and ozone data over Macquarie island, Aust. Meteor. Mag., 52(1), 11-21, 2003.

Chane-Ming, F., Faduilhe, D., and Leveau, J.: Latitudinal and seasonal variability of gravity-wave energy in the South-West Indian Ocean, Ann. Geophys., 25, 2479-2485, 2007, http://www.ann-geophys.net/25/2479/2007/.

Chow, K. C. and Chan, K. L.: Angular momentum transports by moving spiral waves, J. Atmos. Sci., 60, 2004-2009, 2003.

Chun, H.-Y., Goh, J.-S., and Kim, Y.-H.: Characteristics of inertiogravity waves revealed in rawinsonde data observed in Korea during 20 August to 5 September 2002, J. Geophys. Res., 112, D16108, doi:10.1029/2006JD008348, 2007.

Cot, C. and Barat, J.: Wave-turbulence interaction in the stratosphere: A case study. J. Geophys. Res., 91(D2), 2749-2756, doi:10.1029/JD091iD02p02749, 1986.

Danielsen, E. F.: In situ evidence of rapid, irreversible, vertical transport of lower tropospheric air int the lower tropical stratosphere by convective cloud turrets and by larger scale upwelling in tropical cyclones, J. Geophys. Res., 98(D5), 8665-8681, 1993.

Dhaka, S. K., Takahashi, M., Shibagaki, Y., Yamanaka, M. D., and Fukao, S.: Gravity wave generation in the lower stratosphere due to passage of the typhoon 9426 (Orchid) observed by the MU radar at Shigaraki (34.85 N, 136.10E), J. Geophys. Res., 108(D19), doi:10.1029/2003JD003489, 2003.

Eckermann, S. D. and Vincent, R. A.: Falling sphere observations of anisotropic gravity wave motions in the upper stratosphere over Australia, Pure Appl. Geophys., 130, 509-532, 1989.

Eckermann, S. D.: Hodographic analysis of gravity waves: relationships among Stokes parameters, rotary spectra and cross- spectral methods, J. Geophys. Res., 101(D14), 19169-19174, 1996.

Fitzgibbon, A., Pilu, M., and Fisher, R. B.: Direct least-squares fitting of ellipses, IEEE Transactions on Pattern Analysis and Machine Intelligence, 21(5), 476-480, 1999.

Gill, A. E.: Atmosphere-Ocean Dynamics, Academic Press., Inc., 662 p., 1982.

Guest, F., Reeder, M., Marks, C. J., and Karoly, D. J.: InertiaGravity wave observed in the lower stratosphere over Macquarie Island, J. Atmos. Sci., 57, 737-752, 2000.

Guest, F., Reeder, M. J., and Chane-Ming, F.: Analyses of inertiagravity waves in upper-air soundings made from Macquarie Island, Aust. Meteor. Mag., 51(2), 107-115, 2002.

Halir, R. and Flusser, J.: Numerically Stable Direct Least Squares Fitting of Ellipses, in: Proc. Int. Conf. in Central Europe on Computer Graphics, edited by: Skala, V., Visualization and Interactive Digital Media., 125-132, 1998.

Hendricks, E. A., Schubert, W. H., Fulton, S. R., and McNoldy, B. D.: Spontaneous-adjustment emission of inertia-gravity waves by unsteady vortical motion in the hurricane core, Q. J. Roy. Meteorol. Soc., 435-465, 2008.
Hung, R. J.: Observation of upper atmospheric disturbances caused by hurricanes and tropical storms, Space Res., 17, 205-209, 1977a.

Hung, R. J.: Prediction of tornadoes and typhoons (hurricanes) by using gravity wave diagnostics, Atmos. Sci., 4, 48-65, $1977 \mathrm{~b}$.

Hung, R. J. and Kuo, J.: Ionospheric observation of gravity waves associated with hurricane Eloise, J. Geophys., 45(1), 67-80, 1978a.

Hung, R. J., and Smith, R. E.: Ray tracing of gravity waves as a possible warning system for tornadic storms and hurricanes, J. Appl. Meteor., 17, 3-11, 1978b.

Karoly, D. J., Roff, G. L., and Reeder, M. J.: Gravity wave activity associated with tropical convection detected in TOGA COARE sounding data, Geophys.Res. Lett., 23, 261-264, 1996.

Kim, S.-Y., Chun, H.-Y., and Baik, J.-J.: A numerical study of gravity waves induced by convection associated with Typhoon Rusa, Geophys. Res. Lett., 32, L24816, doi:10.1029/2005GL024662, 2005.

Kim, S.-Y., Chun, H.-Y., and Baik, J.-J.: Sensitivity of typhooninduced gravity waves to cumulus parameterizations, Geophys. Res. Lett., 34, L15814, doi:10.1029/2007GL030592, 2007.

Knupp, K. R., Walters, J., and Biggerstaff, M.: Doppler Profiler and Radar Observations of Boundary Layer Variability during the Landfall of Tropical Storm Gabrielle: J. Atmos. Sci., 63(1), 234-251, doi:10.1175/JAS3608.1, 2006.

Kuester, M. A., Alexander, M. J., and Ray, E. A.: A model study of gravity waves over Hurricane Humberto (2001), J. Atmos. Sci., 65(10), 3231-3246, doi:10.1175/2008JAS2372.1, 2008.

Kuleshov, Y. and de Hoedt, G.: Tropical cyclone activity in the Southern Hemisphere, Bull. Aust. Meteor. Oceanogr. Soc., 16, 135-137, 2003.

Liu, Y., Zhang, D.-L., and Yau, M. K.: A multiscale numerical study of Hurricane Andrew (1992). Part II: Kinematics and inner-core structures, Mon. Weather Rev., 127, 2597-2616, 1999.

Maruyama, T.: Upward ransport of westerly momentum due to disturbances of the equatorial lower stratosphere in the period range of about 2 days - A Singapore data analysis for 1983-1993, J. Meteor. Soc. Japan, 72, 423-432, 1994.

Pfister, L., Chan, K. R., Bui, T. P., Bowen, S., Legg, M., Gary, B., Kelly, K., Proffitt, M., and Starr, W.: Gravity waves generated by a tropical cyclone during the STEP tropical field program: A case study, J. Geophys. Res., 98(D5), 8611-8638, 1993.

Pires, P., Redelsperger, J.-L., and Lafore, J.-P.: Equatorial atmospheric waves and their association to convection, Mon. Weather Rev., 125, 1167-1184, 1997.

Roux, F., Chane Ming, F., Lasserre-Bigorry, A., and Nuissier, O.: Structure and evolution of intense tropical cyclone Dina near La Réunion on 22 January 2002: GB-EVTD analysis of single Doppler radar observations, J. Atmos. Oceanic. Technol., 21, 1501-1518, 2004.

Sato, K.: Small-scale wind disturbances observed by the MU radar during the passage of Typhoon Kelly, J. Atmos. Sci., 50, 518538, 1993.

Schecter, D. A. and Montgomery, M. T.: Conditions that inhibit the spontaneous radiation of spiral inertia-gravity waves from an intense mesoscale cyclone, J. Atmos. Sci., 63, 435-456, 2006.

Schecter, D. A.: The spontaneous imbalance of an atmospheric vortex at high Rossby number, J. Atmos. Sci., 65, 2498-2521, 2008.

Shen, C. S.: The correlations between the typhoon and the foF2 of 
ionosphere, Chinese, J. Space Sci., 2, 335-340, 1982.

Shibagaki, Y., Yamanaka, M. D., Kita-Fukase, M., Hashiguchi, H., Maekawa, Y., and Fukao, S.: Meso-a-scale wind field and precipitating clouds in typhoon 9426, (Orchid) Observed by the MU Radar, J. Meteor. Soc. Japan, 81(2), 211-228, 2003.

Shimizu, A. and Tsuda, T.: Characteristics of Kelvin waves and gravity waves observed with radiosondes over Indonesia, J. Geophys. Res., 102(D22), 26159-26171, 1997.

Shimizu, A. and Tsuda, T.: Seasonal and QBO-related variations in gravity wave activities observed with radiosondes at Bandung, Indonesia, J. Meteor. Soc. Japan, 79(1), 185-200, 2001.

Sridharan, S., Tsuda, T., Nakamura, T., Kozu, T., Mori, S., and Russell, J. M.: Observations of the 7-day Kelvin wave in the tropical atmosphere during the CPEA campaign, J. Meteor. Soc. Japan, 84A, 259-275, 2006.

Sun, L., Wan, W., Ding, F., and Mao, T.: Gravity wave propagation in the realistic atmosphere based on a three-dimensional transfer function model, Ann. Geophys., 25, 1979-1986, 2007, http://www.ann-geophys.net/25/1979/2007/.

Takayabu, Y. N., Lau, K., and Sui, C.: Observationof a Quasi-2-Day Wave during TOGA COARE, Mon. Weather Rev., 124, 18921913, 1996.

Tsuda, T., Ratnam, V., Kozu, T., and Mori, S.: Characteristics of 10day Kelvin wave observed with radiosondes and CHAMP/GPS occultation during the CPEA campaign (April-May, 2004), J. Meteor. Soc. Japan, 84A, 277-293, 2006.
Vincent, R. A. and Fritts, D. C.: A climatology of gravity wave motions in the mesopause region at Adelaide, Australia, J. Atmos. Sci., 44, 748-760, 1987.

Vincent, R. A., Allen, S. J., and Eckermann, S. D.: Gravity wave parameters in the lower stratosphere, in: Gravity wave processes: Their parameterization in global climate models, edited by: Hamilton, K., 7-25, Springer-Verlag, 1997.

Wada, K., Nitta, T., and Sato, K.: Equatorial inertia-gravity waves in the lower stratosphere revealed by TOGA-COARE IOP data, J. Meteor. Soc. Jap., 77, 721-736, 1999.

Wheeler, M. and Kiladis, G. N.: Convectively-coupled equatorial waves: Analysis of clouds and temperature in the wavenumberfrequency domain, J. Atmos. Sci., 56, 374-399, 1999.

Yau, M. K., Liu, Y., Zhang, D.-L., and Chen, Y.: A Multiscale Numerical Study of Hurricane Andrew (1992). Part VI: Small Scale Inner-Core Structure and Wind Streaks, Mon. Weather Rev., 132, 1410-1433, 2004.

Zhang, F., Plougonven, R., and Wang, S.: Uncertainties in using the hodograph method to retrieve gravity-wave characteristics from individual soundings, Geophys. Res. Let., 31, L11110, doi:10.1029/2004GL019841, 2004. 